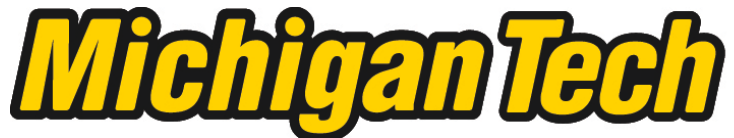 \\ Michigan Technological University Create the Future Digital Commons @ Michigan Tech
}

Dissertations, Master's Theses and Master's Reports - Open

Dissertations, Master's Theses and Master's

Reports

2012

\section{Wolf habitat selection at the territory level : seasonal and interannual variation and influence on reproductive success}

Alessia Uboni

Michigan Technological University

Follow this and additional works at: https://digitalcommons.mtu.edu/etds

Part of the Forest Sciences Commons

Copyright 2012 Alessia Uboni

\section{Recommended Citation}

Uboni, Alessia, "Wolf habitat selection at the territory level : seasonal and interannual variation and influence on reproductive success", Dissertation, Michigan Technological University, 2012.

https://doi.org/10.37099/mtu.dc.etds/135

Follow this and additional works at: https://digitalcommons.mtu.edu/etds

8 Part of the Forest Sciences Commons 
WOLF HABITAT SELECTION AT THE TERRITORY LEVEL: SEASONAL AND INTERANNUAL VARIATION AND INFLUENCE ON REPRODUCTIVE SUCCESS

By

Alessia Uboni

\begin{abstract}
A DISSERTATION
Submitted in partial fulfillment of the requirements for the degree of DOCTOR OF PHILOSOPHY

In Forest Science
\end{abstract}

MICHIGAN TECHNOLOGICAL UNIVERSITY

2012

(C) 2012 Alessia Uboni 
This dissertation has been approved in partial fulfillment of the requirements for the Degree of DOCTOR OF PHILOSOPHY in Forest Science.

School of Forest Resources and Environmental Science

\author{
Dissertation Advisor: Dr. John A. Vucetich \\ Committee Member: $\quad$ Dr. Joseph K. Bump \\ Committee Member: $\quad$ Dr. Michael J. Falkowski \\ Committee Member: Dr. Thomas Werner
}

School Dean: Dr. Terry Sharik 


\section{Table of Contents}

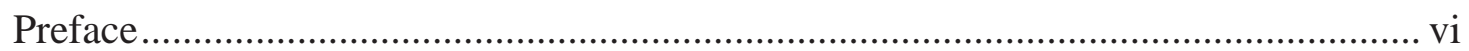

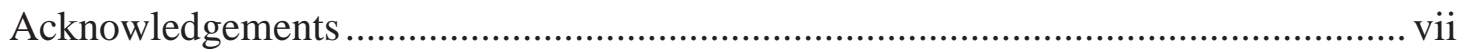

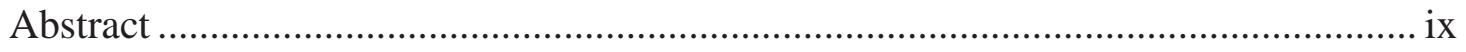

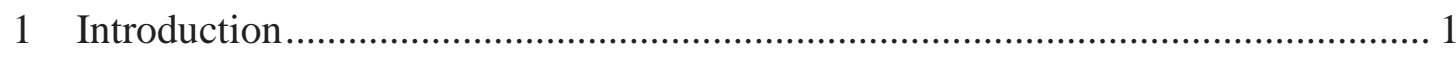

1.1 The study of habitat selection ................................................................... 1

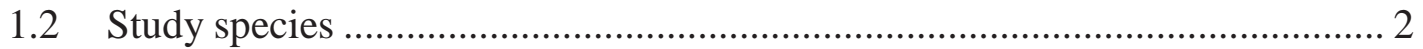

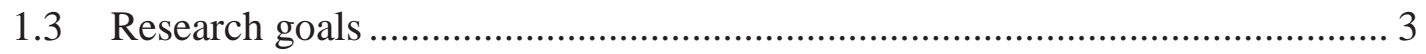

2 Temporal variability in wolf habitat selection ....................................................... 4

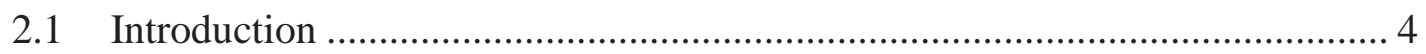

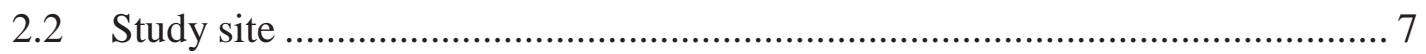

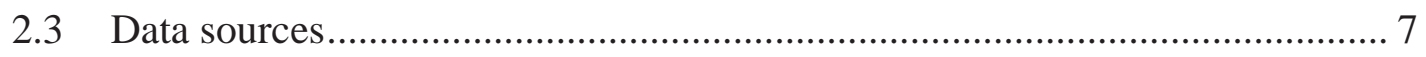

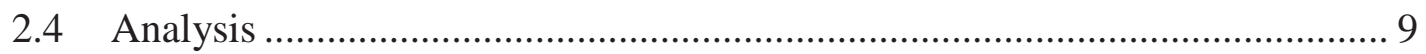

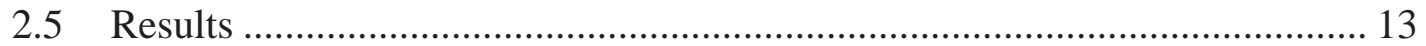

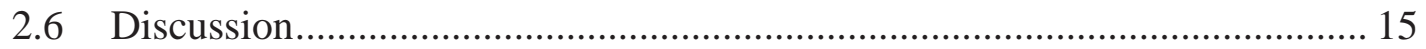

2.7 Supplementary Materials ........................................................................... 27

3 Using interannual variability in habitat use to better understand habitat selection in

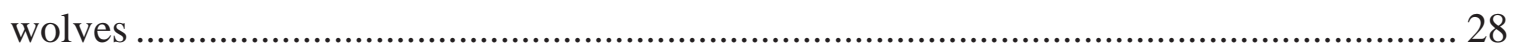

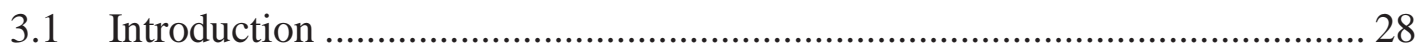

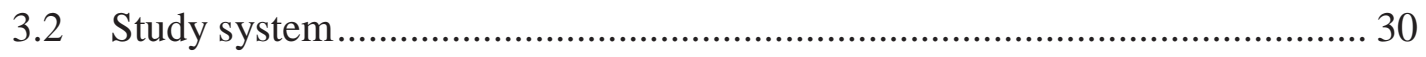

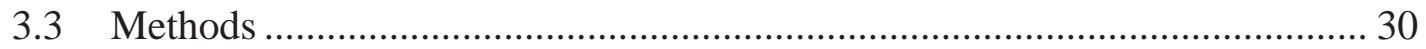

3.3.1 Field methods and location data............................................................... 30

3.3.2 Assessing interannual variability ............................................................... 31

3.3.3 Regression Analyses ....................................................................... 32 


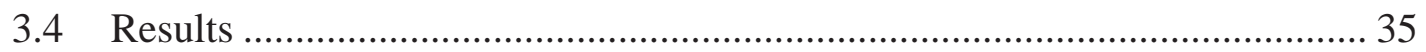

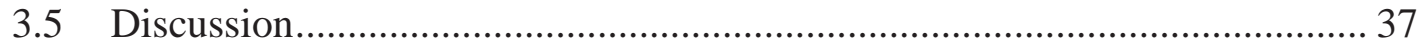

4 The influence of habitat selection on wolf reproductive success ......................... 51

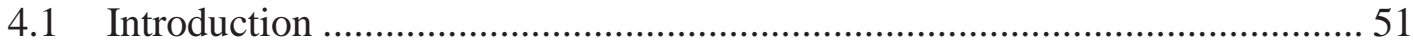

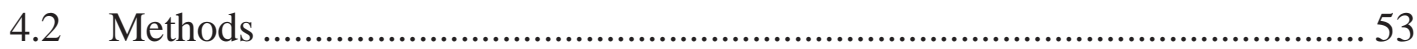

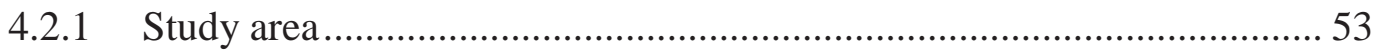

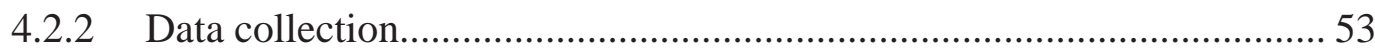

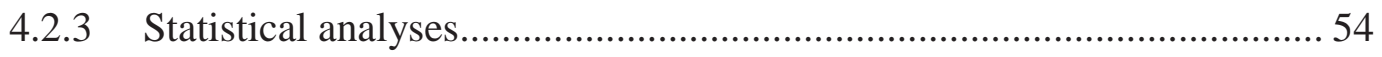

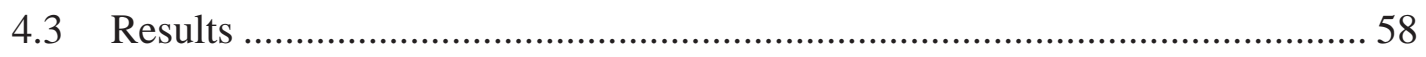

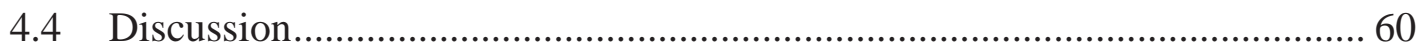

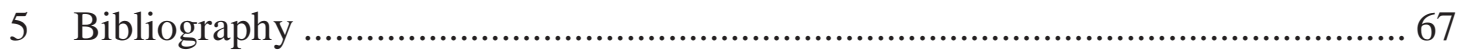




\section{PREFACE}

In this dissertation, Alessia Uboni performed the data analysis. Dr. Doug W. Smith (leader of the Yellowstone Wolf Project) collected the radiotelemetry and wolf count data. Dr. Julie S. Mao developed some of the habitat coverages that were used in the analysis. Dr. Daniel R. Stahler collected the wolf reproductive data. Finally, Dr. John A. Vucetich provided guidance through the analysis and writing processes. 


\section{ACKNOWLEDGEMENTS}

I would like to thank my advisor, Dr. John Vucetich, for the valuable guidance he provided during these years. He helped me to build an important set of skills in the fields of data analysis and processing, to improve my writing skills, and to become a better thinker. Thanks to him, I feel that I acquired the necessary knowledge to move on to the next step of my life.

I would also like to thank the members of my dissertation committee, Dr. Joseph Bump, Dr. Michael Falkowski, and Dr. Thomas Werner, for their support and their help with codes, data processing, and for providing valuable feedback on my research. I am thankful to Dr. Ann MacLean for her assistance with ArcGIS every time I needed it. She was always willing to help and to find the time for me. Thanks to Dr. Robert Froese for his help with R codes and regression analysis. Dr. Leah Vucetich was also an important guide in these years and I would like to thank her for being always available when I needed something, both in my personal and professional life.

I am really thankful to Dr. Doug Smith for giving me the wonderful opportunity of working on this project, for believing in me, and for the important discussions through the analysis and writing processes. Thanks to Mike Coughenour, Dr. Julie Mao, and Dr. Dan Stahler for providing some of the data that I used in my project. I would like to thank also Erin Stahler and Matt Metz as well. They provided data, suggestions, and valuable discussions on the wolves of Yellowstone.

Special thanks to the friends that have helped me when I experienced hard times with software, codes, and technology in general. Thank you to Rudiger Escobar Wolf, Luca d'Eramo, Shawn O'Neil, Julio Rivera, and Riccardo Tortini. 
I owe a big thank you to my family and my friends in Italy. Through their support and existence they have made me feel closer to home, even when time seemed to never pass and the memories of my home country tried to fade.

I am extremely grateful for all the friends in Houghton, MI, that have made this journey memorable. You will always be in my heart and I will miss you immensely. You have made Houghton my second home. You have guided me through hard times that I could have not overcome by myself. It is also thank to you that I was able to fulfill the commitment of getting a Ph.D.

Finally, I would like to thank my funding sources. My research was funded through the National Science Foundation grant DEB 0613730 and by the Yellowstone Foundation. 


\section{ABSTRACT}

Habitat selection has been one of the main research topics in ecology for decades. Nevertheless, many aspects of habitat selection still need to be explored. In particular, previous studies have overlooked the importance of temporal variation in habitat selection and the value of including data on reproductive success in order to describe the best quality habitat for a species. We used data collected from radiocollared wolves in Yellowstone National Park (USA), between 1996 and 2008, to describe wolf habitat selection. In particular, we aimed to identify i) seasonal differences in wolf habitat selection, ii) factors influencing interannual variation in habitat selection, and iii) the effect of habitat selection on wolf reproductive success. We used probability density functions to describe wolf habitat use and habitat coverages to represent the habitat available to wolves. We used regression analysis to connect habitat use with habitat characteristics and habitat selection with reproductive success. Our most relevant result was discovering strong interannual variability in wolf habitat selection. This variability was in part explained by pack identity and differences in litter size and leadership of a pack between two years (summer) and in pack size and precipitation (winter). We also detected some seasonal differences. Wolves selected open habitats, intermediate elevations, intermediate distances from roads, and avoided steep slopes in late winter. They selected areas close to roads and avoided steep slopes in summer. In early winter, wolves selected wetlands, herbaceous and shrub vegetation types, and areas at intermediate elevation and distance from roads. Surprisingly, the habitat characteristics selected by wolves were not useful in predicting reproductive success. We hypothesize that interannual variability in wolf habitat selection may be too strong to detect effects on reproductive success. Moreover, prey availability and competitor pressure may also have an influence on wolf reproductive success, which we did not assess. This project demonstrated how important temporal variation is in shaping patterns of habitat selection. We still believe in the value of running long-term studies, but the effect of temporal variation should always be taken into account. 


\section{INTRODUCTION}

\subsection{The study of habitat selection}

When planning the protection of a wildlife species, conservation managers make decisions on which areas to protect based on scientific studies analyzing the habitat needed by the species. Habitat is the sum of resources (e.g. food, vegetation cover, and distance from roads) that an animal uses on a daily basis. Habitat use is commonly utilized to infer habitat selection and preference of the animal (Garshelis 2000). Habitat preference is defined as the probability of a resource to be chosen by an animal if all resources are available on an equal basis. Habitat selection occurs when the animal actively selects the resources it needs (Johnson 1980).

According to Johnson (1980), habitat selection can be studied at various scales. The larger scale defines the area, or range, that a species occupies (first-order habitat selection). A smaller scale represents the area where an animal settles its home range or territory (second order habitat selection). The smallest scale of selection delineates the habitats that an animal uses inside its home range (third-order habitat selection).

Use-availability studies are one of the most common methods used to describe habitat selection at the territory level (third-order habitat selection). Several techniques have been implemented to conduct these studies. The most common consists of pairing the resources used by the animal at one location of the territory to the resources available to the animal inside the territory boundaries. Then, selection occurs when the animal uses some resources more than expected, based on their availability (Johnson 1980). Among others, Resource Utilization Functions are statistical regression models that can be used to quantify the disproportionate use of resources by animals. In these models, the y variable is an estimate of habitat use and the $\mathrm{x}$ variables are habitat characteristics. Results from use-availability studies are often used to determine the best quality habitat for the species. Then, areas characterized by good quality habitat will be protected by the management plans. 
Often, the pioneer studies in habitat selection focus on the first and second-order habitat selection. Once the distribution of a species is known, the following step consists of analyzing what habitats the species uses at a smaller spatial scale. In many cases, small-scale studies allow the identification of different patterns of species habitat selection, which may otherwise be overlooked when wide ranges are examined.

\subsection{Study species}

Wolves (Canis lupus) are large carnivores that live in North America and Eurasia. They live in packs and prey on a variety of species. Wolf pups are born between April and May, depending on the region, and their life is centered on the den for at least two months and on rendezvous sites during the whole summer (approximately until the end of August). During the pup-rearing season, adult wolves periodically go back to the den or rendezvous sites to feed the pups (Mech and Boitani 2003). While in the pup-rearing season wolves move as small groups of 2-3 animals, in the fall pups start to follow the rest of the pack. It is not until mid-November, though, that the pack starts to move as a cohesive group (Mech and Boitani 2003).

Habitat selection studies have shown that wolves are habitat generalists at large spatial scale (Mladenoff et al. 1995; Mech and Boitani 2003; Oakleaf et al. 2006). That is, they establish their territories in areas with abundance of prey and low human density. At a small spatial scale, wolf habitat selection is more complicated. Wolves prefer habitats located at low elevations, on moderate slopes and southeast-southwest and southwestnorthwest aspects (Paquet et al. 1996; Ciucci et al. 2003; Arjo and Pletscher 2004; Oakleaf et al. 2006; Whittington et al. 2011). Several studies demonstrated that in winter wolves avoid steep slopes, deep snow, and use more open areas (Paquet et al. 1996; Ciucci et al. 2003; Whittington et al. 2005; Hebblewhite and Merrill 2008; Houle et al. 2010; Milakovic et al. 2011; Whittington et al. 2011; Lesmerises et al. 2012). Wolves 
generally use dirt roads for travelling (Ciucci et al. 2003; Eriksen et al. 2009). Primary roads can be used or avoided depending on the intensity of use by humans. In some areas, wolves travel on primary roads because roads make locomotion and prey encountering easier (James and Stuart-Smith 2000; Houle et al. 2010; Whittington et al. 2011;

Lesmerises et al. 2012). On the contrary, in other areas wolves avoid main roads because of possible encounters with humans (Ciucci et al. 2003; Jędrzejewski et al. 2004;

Whittington et al. 2005; Jędrzejewski et al. 2008; Latham et al. 2011; Whittington et al. 2011).

In the pup-rearing season (summer), wolves use forested areas at high elevations to build the den and more open areas and partially treed areas as rendezvous sites (Joslin 1967; Mech 1970; Ballard and Dau 1983; Ream et al. 1989; Matteson 1992; Arjo and Pletscher 2004). In Yellowstone National Park (USA), though, dens are usually built at low elevations (Thurston 2002). Arjo and Pletscher (2004) found that in north-western Montana, in the summer, wolves use more open areas, probably in relation to the location of rendezvous sites.

\subsection{Research goals}

This research project aims to advance our knowledge on wolf habitat selection at small spatial scale. The three main tasks of this project are: 1) identifying differences in wolf habitat selection among seasons; 2) assessing interannual variability in wolf habitat selection and its causes; and 3) describing the best quality habitat for wolves based on reproductive success data. The rationale for pursuing each of these topics is explained in each of the chapters that follow. 


\section{TEMPORAL VARIABILITY IN WOLF HABITAT SELECTION}

\subsection{Introduction}

Temporal variation is an important aspect of wildlife habitat selection. Two main factors that can influence habitat selection include: (i) changes in the habitat and resources available to the animal, and (ii) changes in the activities performed by the animal.

The habitat and the resources available to the animal can vary for several different reasons, such as climate and environmental conditions, competitor pressure, food availability, and predator presence. For instance, Zweifel-Schielly et al. (2009) highlighted how red deer (Cervus elaphus) habitat selection changes among seasons due to the changing availability in high-quality food. Blanchfield et al. (2009) found that reduced habitat availability for lake trout (Salvelinus namaycush) in winter significantly changes habitat selection of the species between winter and summer seasons. Variability in the availability of resources can also occur over longer time periods, such as years. Szaro et al. (1990) stated that habitat selection of forest birds changes over the years because of varying climatic conditions. Marks and Marks (1988) reported that different habitats are used by Columbian sharp-tailed grouse (Tympanuchus phasianellus columbianus) in different years in order to adapt to the changing food availability. It is important to take all these factors into account and divide the study period in smaller time fractions, when possible. For example, Pauley et al. (1993) accounted for changes in snow depth for the habitat selection of white-tailed deer (Odocoileus virginianus) by dividing the winter season in three shorter periods. Mauser et al. (1994) considered two separate seasons at the time of reproduction of mallards (Anas platyrhynchos) to account for differences in water availability and vegetation.

Habitat selection is also altered considerably over time depending on the activities performed by the animal. For example, the needs of an animal during the mating and young-rearing periods can introduce variability in its choices of habitat (Chamberlain et al. 2003). Moreover, daily activities, such as resting, feeding, and traveling, can also 
influence habitat selection within the day. Penne and Pierce (2008) analyzed the habitat selection of adult common carp (Cyprinus carpio) and found seasonal differences between the spring spawning period and the fall and winter seasons. Rasmussen and Litzgus (2010) also highlighted the importance of analyzing habitat selection at different times during the year, based on their study on spotted turtles (Clemmys guttata). They stated that it is important to study a species during several seasons, in order not to miss significant differences in habitat selection among them.

To date, our understanding of seasonal variation in habitat selection of wolves (Canis lupus) is limited to distinguishing between two seasons, summer and winter (e.g., Thurber et al. 1994; Mladenoff et al. 1995; Ciucci et al. 2003; Arjo and Pletscher 2004; Oakleaf et al. 2006; Hebblewhite and Merrill 2008; Latham et al. 2011). This distinction is important because wolf's relationship with prey and the wolf's life history differ greatly during summer and winter. Specifically, during the winter wolves' prey are more vulnerable and more available to wolves because of poor health conditions and poor foraging grounds that force them into areas of higher predator density (Mao et al. 2005). During summer, however, prey are more fit and can disperse across larger areas, becoming less available to predators. Moreover, during the summer wolves raise their pups and their movements are restricted by the need of protecting and hiding them from humans and other wolves (Jędrzejewski et al. 2001; Mech and Boitani 2003; Merrill and Mech 2003). While the distinction between summer and winter is important, the wolf's relationship with prey involves other relevant seasonal variations that require distinguishing more than just two seasons. In early winter, prey are usually still fit and less available to predators. In late winter, prey become weaker and easier to catch. Hence, in early winter wolves probably spend more time searching for prey, i.e. traveling (Mech and Boitani 2003), and rely more on habitat characteristics as part of their hunting strategy than during late winter.

Habitat preferences during a particular season of the year may be critically important for the viability of a wolf population. Failure to assess habitat preferences while paying attention to season variability could cause a manager to overlook the relevance of a particular type of habitat and fail to protect it. 
The purpose of this study is to examine temporal variability in wolf habitat selection in a more detailed manner than has previously been conducted. Specifically, an assessment will be performed to identify differences between three seasons: (i) late winter (January - March), (ii) summer (April - September), and (iii) early winter (October - December). Data collected from radiocollared wolves in Yellowstone National Park and models of habitat selection will be used to assess wolf habitat selection in each season, at a territory level (Johnson 1980). We expect that wolf's life history and prey vulnerability generate differences in wolf habitat selection based on season. 


\subsection{Study site}

The Northern Range of Yellowstone National Park (YNP) is an area of approximately $1500 \mathrm{~km}^{2}$, situated in the northern part of the park and embracing some land outside the park boundary (Lemke et al. 1998). Elevation ranges between 1,500 and 3,200 meters ( $80 \%$ of the area has an elevation between 1800 and 2500). An average of $25 \mathrm{~cm}$ of precipitation falls every year, a third of it falling as snow (Farnes et al. 1999). Valley bottoms in the eastern and north-western part of the Northern Range are characterized by grasslands and shrub steppe. The most common species are big sagebrush (Artemisia tridentate) and Idaho fescue (Festuca idahoensis) (Despain 1990). Forests are

predominant in the valley bottoms of the central part of the Northern Range and at higher elevations throughout the area. Lodgepole pine (Pinus contorta) is the predominant species, but some forests also include subalpine fir (Abies lasiocarpa), Engelmann spruce (Picea engelmannii), and whitebark pine (Pinus albicaulis). Aspen (Populus tremuloides) stands are becoming more common in the park, thanks to the wolf pressure as a predator that keeps elk far from riparian zones (Ripple and Larsen 2000). Primary roads are open to the public traffic year around and more than $75 \%$ of the Northern Range area is closer than $7 \mathrm{~km}$ to these roads. Moreover, the $97 \%$ of the Northern Range is closer than $5 \mathrm{~km}$ to any main watercourse.

In the Northern Range, elk (Cervus elaphus) are the main prey of wolves (Smith et al. 2004). Other ungulates are present, such as bison (Bison bison), moose (Alce alce), and white-tailed deer.

\subsection{Data sources}

Wolf location data. - The data used in this study were collected from 1998 to 2007 from wolves equipped with VHF (Very High Frequency) radiocollars ( $n=289$; radiocollars manufactured by Telonics, Inc. Mesa, AZ) and from 2001 to 2007 from GPS (Global Positioning System) radiocollared wolves $(n=34$; radiocollars manufactured by Televilt Lindesberg, Sweden, Telonics, Inc. Mesa, AZ, and Lotek, Newmarket, ON, Canada). Both data sets contained locations registered in Universal Transverse Mercator 
(UTM) coordinates in North American Datum 1983. GPS locations were collected from VHF radiocollared wolves from an airplane, attempting to locate each pack at least once per day during winter studies (in March, and between mid-November and midDecember) and approximately once per week during the rest of the year. GPS radiocollars collected wolf locations automatically every 30 minutes in the summer and every 3 hours in the winter, during both day and night time. Additional details on capture, handling, and location of wolves are available in Metz et al. (2011).

Since locations gathered from VHF radiocollared wolves were collected during sunlight hours only, we filtered the locations collected from GPS radiocollars in order to leave only GPS locations acquired during the day. We then imported the two datasets in a Geographic Information System (GIS), ArcGIS (Environmental Systems Research Institute, Redlands, California, USA), and divided the radiotelemetry locations by season, i.e. late winter (January - March), summer (April - September), and early winter (October - December). To avoid temporal correlation between locations collected in the same day from different members of the same wolf pack, we randomly selected one location per pack per day for the early winter and late winter seasons. Since wolves can cover their entire territory within 24 hours (Mech 1970), locations collected more than 24 $\mathrm{h}$ apart are unlikely correlated to each other (Otis and White 1999). On the other hand, in the summer packs are less cohesive than in the winter (Metz et al. 2011). Pack members form smaller groups that travel independently from each other inside the pack territory (Mech and Boitani 2003). For this reason, one location per group per day gives an appropriate sample size that is not affected by temporal autocorrelation. We performed these random selections with the extension Hawth's Analysis Tools for ArcGIS (Beyer 2004).

Habitat data. - Habitat characteristics and topographic data were extracted from the Greater Yellowstone Ecosystem GIS coverages of vegetation type (veg), elevation (elev), slope (slope), habitat openness (open), distance from rivers (rivers), distance from primary roads (roads), and snow water equivalent, SWE (Farnes and Romme 1993). Vegetation type was represented by a land cover coverage created in 2001 by the Multi- 
Resolution Land Characteristics Consortium (MRLC,

http://www.mrlc.gov/nlcd_multizone_map.php). This coverage has a $30 \mathrm{~m}$ cell resolution and 19 vegetation classes, of which 15 present in the park. We reclassified the vegetation coverage by reducing the number of classes to six: open water, developed (including all four "Developed" categories of the original data set), herbaceous (including barren land, grassland/herbaceous, sedge/herbaceous, and pasture hay), forest (including deciduous, evergreen, and mixed forest), shrub, and wetlands (including woody and emergent herbaceous wetlands). The habitat openness coverage was calculated by Mao et al. (2005). This coverage represents the percentage of open-habitat pixels at a distance smaller than $400 \mathrm{~m}$ from each grid cell (25-m cell resolution). Elevation (in meters) and slope (in degrees) were obtained from a 30-m Digital Elevation Map (DEM). Distance from roads and rivers (in meters) were calculated as the Euclidean distance between each grid cell (25-m cell resolution) and the nearest primary road or major watercourse (defined as a watercourse longer than $20 \mathrm{~km}$ ). A 30-m buffer was drawn around each liner feature (road or river) prior to developing the "distance from road/river" coverages. For winters, the Yellowstone snow model (Wockner 2002) was used to develop snow maps representing SWE in $\mathrm{mm}$. A map representing average SWE was developed by Mike Coughenour for each early and late winter.

Additionally, elk distribution maps were developed from the Post-wolf-W Resource Selection Functions proposed by Mao et al. (2005) for summer (2000-2002) and winter seasons (late winter 2001 and 2002, early winter 2000 and 2001), as a representation of prey distribution (elk) in the Northern Range of the park.

\subsection{Analysis}

Overview. - To assess seasonal differences in wolf habitat selection, we constructed and compared sets of resource utilization functions, RUFs (sensu, Marzluff et al. 2004). We developed RUFs for ten packs observed over a ten-year period (1998-2007) and a subset of that sample involving six packs observed over a three-year period (2000-2002). The smaller sample was valuable because, for that period of time, we also had data 
pertaining to the spatial distribution of elk, which is presumed to be an important aspect of wolf habitat selection.

Resource Utilization Functions. - Each RUF was a mixed-effect regression model (see below) with utilization distribution (UD) values as the response variable and habitat characteristics as candidate predictor variables. A UD is a probability density function [ $\hat{f}_{U D}(x, y)$ at location $\left.(\mathrm{x}, \mathrm{y})\right]$ that describes how intensely an animal uses each part of its territory (Seaman and Powell 1996). We estimated the UDs using wolf radiotelemetry data and the fixed kernel technique (Seaman and Powell 1996; Kernohan et al. 2001). Radiotelemetry locations representing extraterritorial forays were discarded from the analysis. We used the plug-in method for bandwidth selection (Wand and Jones 1995; Gitzen et al. 2006), available in the ks package for R (R Development Core Team 2012). Using ArcGIS, we removed the outer 5\% of the UDs, because the tails of a distribution are typically less reliably estimated (Vanak and Gompper 2010). We also rescaled the UDs to range from 0 to 95, where 0 represents no use. Each UD was specific to a particular pack, year, and season (i.e., early winter [EW], late winter [LW], and summer [S]). Fifteen wolf packs had enough location (>30) from which to build UDs.

Each RUF was computationally complex, including random effect terms, additive terms, spatial autocorrelation functions, and a large sample size. This complexity caused the $m g c v$ and nlme packages in $\mathrm{R}$ (R Development Core Team 2012) to abort before completing the computations. Consequently, we drew a stratified subsample from the full sample. In particular, we began by dividing the range of observed UD values into bins (i.e., 6-15, 16-25,.. 86-95). UD values between 0 and 5 were discarded (since they represent extremely low use areas). Values from 96 to 100 were already excluded since our UDs represent $95 \%$ of a pack territory (see above). For each pack/year/season, we sampled 200 observations from each bin, giving a total of 1800 observations per pack/year in each season. Because this subsample was also too large, we applied the same procedure a second time once all the pack/year data sets were combined together by season. We obtained 1800 observations per season for the 3-year data set. For the 10-year 
data set, we were able to obtain results after the sample had been reduced to 3600 observations per season.

Short-term habitat selection analysis. - For the three-year data set, which included the spatial distribution of elk, we built three sets of models, one for each season. We evaluated each model based on p-values, AIC (Akaike Information Criterion, Akaike 1974), and diagnostic tools such as residual plots. To assess seasonal differences in habitat selection, we identified the best model for each season and then compared the coefficients of those models (Table 2.3). We used Welch's tests to compare linear terms and variable coefficient models to compare additive terms (see Suppl. Materials for details; Hastie and Tibshirani 1990; Mao et al. 2005; see also page 60 of Zuur et al. 2009).

For each season, we built six models. The purpose of the first five models was to identify the most parsimonious model structure in terms of requiring additive terms, random-effect terms, and spatial autocorrelation. Following Zuur et al. (2009), we made these assessments while including all the candidate predictors. In particular, for each season we built a model including: 1) only linear terms (LW1, S1, EW1), 2) linear terms for most variables and additive terms for those variables that exhibited signs of nonlinearity, calculated from cubic regression splines (see page 43 in Zuur et al. 2009; Models LW2, S2, and EW2), 3) linear terms, additive terms, and a random intercept to account for a year effect, Year (LW3, S3, EW3), and 4) linear terms, additive terms, and a random intercept to account for a pack effect, Pack (LW4, S4, EW4). For late winter and summer, the fourth model outperformed the other three models (Table 2.1). Nevertheless, in early winter model LW2 performed best. To make the models comparable and to avoid the computational difficulties that we encountered when applying a spatial autocorrelation function to a fixed-effect additive model, we decided to proceed with the forth model (EW4) also for early winter. As such, for each season we built a fifth model that included all the terms of the fourth model, plus a spatial autocorrelation structure applied to the model residuals (LW5, S5, EW5). This fifth model outperformed all the others. As such, the last model we build was characterized by 
the same basic structure, but excluded any predictor that was not statistically significant (LW6, S6, EW6).

We also inspected the models for outliers and the predictor variables for multicollinearity (threshold: $r=0.6$ ). Collinearity was high between SWE and elev (Pearson's correlation coefficient: $r=0.84$ in late winter; $r=0.89$ in early winter) and between $e l k$ and $e l e v$ in the summer data set $(r=0.81)$. Therefore, we dropped SWE in the winter models and elk in the summer models. We decided to retain elev as a predictor in our models (instead of SWE for the winter and elk for the summer) in order to be able to directly compare this variables among seasons. We identified one observation as outlier in early winter (Bonferroni p-value < 0.05). Omitting this observation reduced the size of the early winter sample to 1799 observations. The summer sample size was reduced to 1797 observations (see the Suppl. Materials for an explanation).

Long-term habitat selection analysis. - We repeated this entire regression procedure for the ten-year data set, for which information about the spatial distribution of elk was unavailable. Similarly to the three-year sets of models, we excluded SWE as a candidate predictor because it was collinear with elev ( $r=0.83$ in late winter; $r=0.84$ in early winter). We identified an observation as outlier in the summer data set (Bonferroni pvalue < 0.05). The resulting summer data set included 3599 observations. For all the models developed from the ten-year data set, we included Year as a fixed effect rather than a random effect so that we could assess more precisely how each particular year differed from the others. However, we could not include the Year effect for models that accounted for spatial autocorrelation in the early winter data set (models EW10 and EW11, Table 2.2), because those data included 2 out of 3 packs that were observed for only one year. Including Year in those cases would have resulted in division by zero in the variance-covariance matrix that accounts for spatial autocorrelation. 


\subsection{Results}

The goal of our study was to assess if wolf habitat selection changes based on the season we observe. Based on wolf ecology and life history, we expected to find relevant differences among seasons. We used both a short-term data set (3 years) and a long-term data set (10 years) to perform our analysis. We found both similarities and differences among seasons and, unexpectedly, between data sets.

For late winter, the most parsimonious model structure was the same for the shortterm and the long-term data sets and consisted in a complete model including additive terms for roads, rivers, elk, and elev and a random intercept for Pack (Model LW5, Table 2.1; Model LW10, Table 2.2). For summer and early winter, the best models were the reduced models S6, EW6, EW11, and S11 for both data sets (for details see Table 2.1 and Table 2.2). Despite this similarity among data sets, there were considerable differences among seasons and between the short and long-term data sets (Table 2.3).

For both the short-term and the long-term data sets, wolves did not exhibit preferences for various vegetation cover types during the summer or during late winter. During early winter, they exhibited preferences in the 3-year data set, but not in the 10-year data set (Table 2.3). This result may indicate the existence of a strong year effect on early winter habitat selection. The strongest preferences exhibited in the early winter 3-year dataset were for wetlands and habitats dominated by herbaceous and shrub cover (Figure 2.1).

Wolves had a preference for shallower slope only during late winter (3-year dataset, $p$ $=0.02)$ and summer $(10$-year dataset, $\mathrm{p}=0.01)$. They exhibited a preference for open habitats during late winter ( 3 -year dataset, $\mathrm{p}=0.01$ ) and early winter (3-year dataset, $\mathrm{p}=$ 0.05). However, the preference for open habitats was significantly different between the two seasons $\left(\mathrm{t}=49.31 ; \mathrm{p}<10^{-3}\right)$.

Wolves preferred portions of their territory that were at intermediate distances (2-3 $\mathrm{km}$ ) from primary roads for all three seasons and for both data sets, except during summer for the 3-year dataset (Figure 2.2; Table 2.3). Nevertheless, this preference was significantly different among seasons, based on our variable coefficient models $\left(\mathrm{p}<10^{-3}\right.$ 
in late and early winter for both data sets; summer $\mathrm{p}=0.60$ in the long-term data set; summer $\mathrm{p}=0.02$ in the short-term data set).

Wolves selected for intermediate elevations $(2000-2300 \mathrm{~m})$ in late winter (10-year data set) and in early winter (3-year data set; Figure 2.3). They had no preference with respect to distance from rivers.

We assessed the impact of elk distribution on wolf habitat selection only for the 3-year dataset. Elk was not included in the summer models because of collinearity with elevation. In early and late winter, wolf habitat selection was not influenced by elk distribution (elk was dropped in the best-performing early winter model and nonsignificant in the late winter model, Table 2.3).

We assessed the influence of Year only for the 10-year summer and late winter data sets. We observed important differences in both seasons among years (year 1999 in late winter and 1998 in summer; see Table 2.3 and Figure 2.4). This result indicates that the distribution of UD values (i.e., habitat use) differs among years. 


\subsection{Discussion}

Our analysis was based on the idea that seasonal differences in wolves' life history and relationship with prey may influence the habitat that the species selects in different seasons. Indeed, we found several important dissimilarities among seasons (see below). At the same time, our most remarkable finding was revealing not only seasonal differences in habitat selection, but also differences among years. In particular, the year effect on habitat selection was significant in our long-term late winter and summer habitat models (Table 2.3) and we also obtained significant differences from the two data sets we analyzed (encompassing two different lengths of time). We explore these results in more detail below.

Interannual differences in habitat selection. - We detected several significant patterns in our short-term data set that were not detected in our long-term data set. In particular, based on the short-term data set wolves avoided steep slopes and selected for open habitats in late winter. Furthermore, they selected for wetlands, herbaceous and shrub habitats, open habitats, and intermediate elevations in early winter. These patterns were not revealed in the long-term data set. The most likely explanation for this difference is that patterns in wolf habitat selection varied from year to year. Even though we could not assess the impact of Year on wolf habitat selection in early winter, we obtained strongly different results for this season from the analysis of the short and long-term data sets. We can therefore hypothesize that the year effect is indeed significant in this season. Overall, we conclude that differences among years are relevant in all seasons. These differences may be due to interannual differences in climate, prey availability, competitors' pressure, and properties of a pack (e.g. pack size and litter size).

This result has implications for habitat research in general, which is almost always based on analyses that neglect interannual differences in habitat selection or depend on data sets that are too short to assess interannual differences. For example, we selected four top journals in the fields of wildlife ecology and management (Ecology, Journal of Animal Ecology, Oikos, and Journal of Wildlife Management) and searched for all the 
studies on habitat selection published between 2002 and 2012 and conducted on more than one year of data. Among the 23 papers that we found, only $35 \%$ of them recognized that a year effect might influence the results of a long-term analysis. In these studies, the year effect was taken into consideration either by developing different models for each year or by using mixed-effect models. Nevertheless, the majority of the papers we reviewed did not consider potential interannual differences in habitat selection.

Seasonal differences. - The most striking seasonal difference we observed is the complexity of wolf habitat selection in late and early winter, compared to its simplicity in summer. Essentially, wolves do not exhibit habitat preferences in summer (except for distance from roads) and habitat selection in summer is very variable over the years (see Table 2.3). By contrast, wolves select for more habitat characteristics in winter and the differences among years are less pronounced. We hypothesize that the fact that wolf packs divide into smaller groups during the summer may have hidden some patterns of habitat selection in our analysis. More precisely, let us imagine that the pack splits into a group that takes care of the pups and the other that patrols the territory. The habitat selected by the two groups will be different, because one group will visit the den or rendezvous site periodically, while the other will select a habitat suitable for travelling. If we pool together the data collected from these two groups, we might not see any precise pattern in habitat selection. On the contrary, in winter packs travel as one group and it may be easier to reveal patterns of habitat selection.

Roads. - Wolves' selection of habitat in relationship to roads has been a perennial interest to wolf ecologists. For this reason, we highlight the results of our analysis as they pertain to roads. Overall, wolves always avoided areas more than $4 \mathrm{~km}$ away from primary roads (Figure 2.2). Moreover, we found a consistent pattern in late winter, when wolves preferred intermediate (about $3 \mathrm{~km}$ ) distances from roads, based both on our short and long-term analyses. Even though early winter selection of distance from roads seemed to be similar in both our data sets, the use of generalized additive models allowed us to detect a small difference. From the 3-year analysis, wolves seemed to avoid areas 
closer to roads, select intermediate distances, and avoid areas further from roads in early winter. Looking at a longer time frame, though, wolf selection for intermediate distances from roads seemed mitigated by the strong year effect and our results showed that wolves actually selected equally areas at short and intermediate distances from roads and avoided areas at longer distances. Lastly, based on the 3-year analysis wolves preferred areas closer to roads in the summer, while based on the long-term analysis they preferred intermediate distances. Conflicting results can also be found in the literature. Some studies hypothesized that wolves select primary roads, either in summer and/or winter, as paths where locomotion is easier or to enhance the chances of encountering a prey (James and Stuart-Smith 2000; Houle et al. 2010; Whittington et al. 2011; Lesmerises et al. 2012). On the contrary, based on other studies wolves avoid main roads because of possible encounters with humans (Ciucci et al. 2003; Jędrzejewski et al. 2004; Whittington et al. 2005; Jędrzejewski et al. 2008; Latham et al. 2011; Whittington et al. 2011). Clearly, on a local basis wolves have to make a tradeoff between the advantages that linear human infrastructure provide (e.g., ease of movement and higher prey encounter rates) and the disadvantages, like risk of collision with motor vehicles and direct hunting. The intensity of use of roads by wolves is therefore a compromise between the intensity of human disturbance and the benefits that these linear features provide. Indeed, wolves use secondary roads and trails more consistently than primary roads (Ciucci et al. 2003; Whittington et al. 2005), since secondary roads are usually less used by humans.

Elk. - Surprisingly, elk distribution was not a good predictor for wolf habitat selection. There are two possible explanations for this phenomenon. First of all, wolves hunt mainly at dusk and dawn (Mech and Boitani 2003). Therefore, elk distribution may be more important in shaping wolf habitat selection at night, rather than during the day. Since we studied daylight habitat selection, the relationship between wolves and prey did not revealed to be significant. During the day, predators' habitat selection patterns may reflect their need to defend their territory boundaries, travel, and rest. Similarly, Dickson et al. (2005) found that cougars (Puma concolor) select different habitats during the night 
compared to daylight hours. This is probably because they rest in bed sites during daylight hours and hunt and travel during the night. Secondly, at small spatial scale predators might select areas in which prey are easier to encounter and kill, rather than areas where prey is more abundant (Hopcraft et al. 2005; Balme et al. 2007; Milakovic et al. 2011). Therefore, prey distribution would not be a good indicator of predator habitat selection.

Additional seasonal differences. - As discussed, wolves did not selected for habitats used by elk and used their territories based on the distance from primary roads differently among seasons. Yet, we found additional dissimilarities among seasons. During late winter, wolves tended to avoid steeper terrains and preferred more open areas (even though this preference was not reflected in selection of any particular vegetation type). Avoidance of steep slopes in winter is a pattern confirmed by many other studies on wolf habitat selection (Ciucci et al. 2003; Whittington et al. 2005; Hebblewhite and Merrill 2008; Houle et al. 2010; Whittington et al. 2011; Lesmerises et al. 2012). Steep terrains may be avoided by wolves during late winter because of their roughness as walking paths, due to the snow accumulation, while open areas may favor travelling (Milakovic et al. 2011). Furthermore, in the Northern Range of Yellowstone National Park elk use open areas in winter (Mao et al. 2005). As coursing predators, wolves may use open areas to facilitate the chase of the prey (Estes and Goddard 1967; Kruuk 1972; Schaller 1972).

Early winter patterns of habitat use were more complicated. In early winter, wolves strongly preferred open habitats, dominated by wetlands, shrubs, and herbaceous plant cover. Wolves also preferred intermediate elevations. Comparing early and late winter use of areas based on elevation, we can see how wolves start avoiding the areas that first get covered with snow (i.e., higher elevations) in early winter and then move to the areas of lower elevation by the second half of the winter (Figure 2.3). This result confirms the findings of previous studies which showed that wolves generally avoid high elevations in winter (Ciucci et al. 2003; Whittington et al. 2005; Hebblewhite and Merrill 2008; Milakovic et al. 2011; Whittington et al. 2011; Lesmerises et al. 2012). 
These results are in accordance with our expectations that wolves would use different habitats at different times during winter.

Conclusions. - Our findings may create a shadow on the importance of analyzing data collected over long periods of time. Nevertheless, we still believe that long-term analyses are the only solution to really understand the habitat requirements of a species. If we based our knowledge of wolf habitat selection on the short-term analysis we conducted, for example, we would get an idea of what the species needs that is misleading and only applicable to years with similar conditions to the ones we studied. On the contrary, if the year effect is taken into consideration (for example as a random term in a mixed-effect model), long-term analyses can reveal more general patterns, better describing the habitat selection of a species as a whole. In particular, our study revealed that wolves are indeed habitat generalists if observed at large spatial and temporal scales, but not in the classic meaning of the word (Mech 1970). Wolves do not simply use any habitat that has abundance of prey and low human disturbance as believed in the past (Fritts et al. 1994; Mladenoff et al. 1995). Instead, they adapt to differences in the environment and show different patterns of habitat selection based on the time (year, season, time of the day) and on the areas in which we observe them (Ciucci et al. 2003; Milakovic et al. 2011). 
Table 2.1. Performance of the Resource Utilization Functions describing wolf habitat selection in the Northern Range of Yellowstone National Park, for a three-year data set (2000-2002). Late winter models were based on 1800 observations from 4 packs, summer models were based on 1797 observations from 5 packs, and early winter models were based 1799 observations from two packs. Correlation function $=$ a correlation function was applied to the model residuals to account for spatial autocorrelation.

\begin{tabular}{|c|c|c|c|c|c|c|c|}
\hline & & \multicolumn{4}{|c|}{ Model Structure } & \multirow[b]{2}{*}{$\Delta_{\mathrm{i}}$} & \multirow[b]{2}{*}{$\mathbf{w}_{\mathbf{i}}$} \\
\hline Season & $\begin{array}{l}\text { Model } \\
\text { code }\end{array}$ & $\begin{array}{l}\text { Model } \\
\text { type }\end{array}$ & $\begin{array}{l}\text { Random } \\
\text { intercepts }\end{array}$ & $\begin{array}{l}\text { Correlation } \\
\text { function }\end{array}$ & $\begin{array}{c}\text { All } \\
\text { available } \\
\text { predictors }\end{array}$ & & \\
\hline \multirow{6}{*}{ 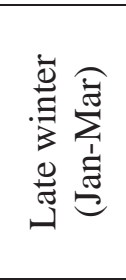 } & L1 & Linear & None & & $\checkmark$ & 3022.16 & 0.00 \\
\hline & L2 & Additive & None & & $\checkmark$ & 2840.51 & 0.00 \\
\hline & L3 & Additive & Year & & $\checkmark$ & 2831.99 & 0.00 \\
\hline & L4 & Additive & Pack & & $\checkmark$ & 2815.58 & 0.00 \\
\hline & L5 & Additive & Pack & $\checkmark$ & $\checkmark$ & 0.00 & 1.00 \\
\hline & L6 & Additive & Pack & $\checkmark$ & & 229.23 & 0.00 \\
\hline \multirow{6}{*}{ 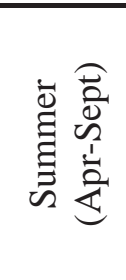 } & S1 & Linear & None & & $\checkmark$ & 2221.11 & 0.00 \\
\hline & S2 & Additive & None & & $\checkmark$ & 2102.14 & 0.00 \\
\hline & S3 & Additive & Year & & $\checkmark$ & 2095.71 & 0.00 \\
\hline & S4 & Additive & Pack & & $\checkmark$ & 1982.39 & 0.00 \\
\hline & S5 & Additive & Pack & $\checkmark$ & $\checkmark$ & 6.14 & 0.04 \\
\hline & S6 & Additive & Pack & $\checkmark$ & & 0.00 & 0.96 \\
\hline \multirow{6}{*}{ 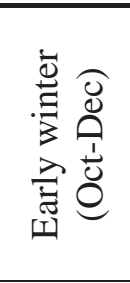 } & E1 & Linear & None & & $\checkmark$ & 682.45 & 0.00 \\
\hline & E2 & Additive & None & & $\checkmark$ & 575.55 & 0.00 \\
\hline & E3 & Additive & Year & & $\checkmark$ & 589.90 & 0.00 \\
\hline & E4 & Additive & Pack & & $\checkmark$ & 586.98 & 0.00 \\
\hline & E5 & Additive & Pack & $\checkmark$ & $\checkmark$ & 4.50 & 0.10 \\
\hline & E6 & Additive & Pack & $\checkmark$ & & 0.00 & 0.90 \\
\hline
\end{tabular}

NOTES: $\Delta_{\mathrm{i}}=$ difference in AIC (Akaike Information Criterion) compared to the lowest scoring model; $\mathrm{w}_{\mathrm{i}}=\mathrm{AIC}$ weights 
Table 2.2. Performance of the Resource Utilization Functions describing wolf habitat selection in the Northern Range of Yellowstone National Park, for a ten-year data set (1998-2007). Sample sizes are: 3600 observations for late winter models (collected on 9 packs), 3599 observations for summer models ( 9 packs), and 3600 for early winter models ( 3 packs). Correlation function $=$ a correlation function was applied to the model residuals to account for spatial autocorrelation.

\begin{tabular}{|c|c|c|c|c|c|c|c|}
\hline \multirow[b]{2}{*}{ Season } & \multirow[b]{2}{*}{$\begin{array}{c}\text { Model } \\
\text { code }\end{array}$} & \multicolumn{4}{|c|}{ Model Structure } & \multirow[b]{2}{*}{$\Delta_{\mathrm{i}}$} & \multirow[b]{2}{*}{$\mathbf{w}_{\mathbf{i}}$} \\
\hline & & $\begin{array}{l}\text { Model } \\
\text { type }\end{array}$ & $\begin{array}{l}\text { Random } \\
\text { intercepts }\end{array}$ & $\begin{array}{l}\text { Structured } \\
\text { correlation }\end{array}$ & $\begin{array}{c}\text { All } \\
\text { available } \\
\text { predictors }\end{array}$ & & \\
\hline \multirow{5}{*}{ 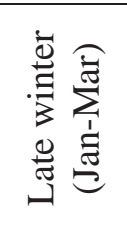 } & L7 & Linear & None & & $\checkmark$ & 2649.81 & 0.00 \\
\hline & L8 & Additive & None & & $\checkmark$ & 2432.57 & 0.00 \\
\hline & L9 & Additive & Pack & & $\checkmark$ & 2427.73 & 0.00 \\
\hline & L10 & Additive & Pack & $\checkmark$ & $\checkmark$ & 0.00 & 1.00 \\
\hline & L11 & Additive & Pack & $\checkmark$ & & 2521.96 & 0.00 \\
\hline \multirow{5}{*}{ 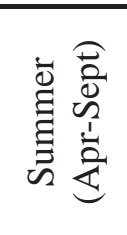 } & S7 & Linear & None & & $\checkmark$ & 3888.01 & 0.00 \\
\hline & S8 & Additive & None & & $\checkmark$ & 3569.23 & 0.00 \\
\hline & S9 & Additive & Pack & & $\checkmark$ & 3374.61 & 0.00 \\
\hline & S10 & Additive & Pack & $\checkmark$ & $\checkmark$ & 9.34 & 0.01 \\
\hline & S11 & Additive & Pack & $\checkmark$ & & 0.00 & 0.99 \\
\hline \multirow{5}{*}{ 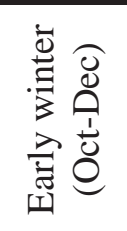 } & E7 & Linear & None & & $\bar{\checkmark}$ & 3376.58 & 0.00 \\
\hline & E8 & Additive & None & & $\checkmark$ & 2862.97 & 0.00 \\
\hline & E9 & Additive & Pack & & $\checkmark$ & 2868.68 & 0.00 \\
\hline & E10 & Additive & Pack & $\checkmark$ & $\checkmark$ & 0.29 & 0.46 \\
\hline & E11 & Additive & Pack & $\checkmark$ & & 0.00 & 0.54 \\
\hline
\end{tabular}

NOTES: $\Delta_{\mathrm{i}}=$ difference in AIC (Akaike Information Criterion) compared to the lowestscoring model; $\mathrm{w}_{\mathrm{i}}=\mathrm{AIC}$ weights 
Table 2.3. Coefficients $(\beta)$, standard errors $(S E)$ and p-values ( $p$; bold if statistically significant) for our best-performing models representing wolf habitat selection (see Table 2.1 and Table 2.2). The table represents two mixed-effect additive models (with Pack as random term) for each season, derived respectively from a 3-year and a 10-year data set. $\beta s$ that were significant for the 10-year data set, but not the 3-year data set, are double underscored. A wavy underscore highlights $\beta$ s that were significant for the 3-year but not the 10-year data set. The categories of the veg predictor variable are marked with * (developed is the reference category). The reference category for Year is 1999 in late winter and 1998 in summer. Variables marked with ** are described by a smoother.

\begin{tabular}{|c|c|c|c|c|c|c|c|}
\hline \multirow[b]{2}{*}{ Variable } & \multirow[b]{2}{*}{ Data } & \multicolumn{2}{|c|}{ Late winter } & \multicolumn{2}{|c|}{ Summer } & \multicolumn{2}{|c|}{ Early winter } \\
\hline & & $\beta$ (SE) & p & $\beta$ (SE) & p & $\beta(\mathrm{SE})$ & p \\
\hline \multirow{2}{*}{ Intercept } & 10 years & $28.62(4.49)$ & $<10^{-4}$ & $30.88(2.21)$ & $<10^{-4}$ & $23.07(2.99)$ & $<10^{-4}$ \\
\hline & 3 years & $-18.19(14.37)$ & 0.21 & $5.3(8.1)$ & 0.51 & $16.24(3.2)$ & $<10^{-3}$ \\
\hline Year 1999 & 10 years & & & $-3.95(1.19)$ & $<10^{-3}$ & - & - \\
\hline Year 2000 & 10 years & $0.3(1.45)$ & 0.83 & $-2.24(1.19)$ & 0.06 & - & - \\
\hline Year 2001 & 10 years & $5.79(1.54)$ & $<0^{-4}$ & $-5.09(1.21)$ & $<10^{-4}$ & - & - \\
\hline Year 2002 & 10 years & $-10.08(1.72)$ & $<10^{-4}$ & $-11.32(1.26)$ & $<10^{-4}$ & - & - \\
\hline Year 2003 & 10 years & $-4.92(1.6)$ & $<0.01$ & $-12.25(1.18)$ & $<\mathbf{1 0}^{-4}$ & - & - \\
\hline Year 2004 & 10 years & $-3.26(1.32)$ & 0.01 & $-7.94(1.32)$ & $<10^{-4}$ & - & - \\
\hline Year 2005 & 10 years & $-1.51(1.53)$ & 0.32 & $-10.09(1.46)$ & $<10^{-4}$ & - & - \\
\hline Year 2006 & 10 years & $0.65(1.92)$ & 0.73 & $-7.92(1.39)$ & $<10^{-4}$ & - & - \\
\hline Year 2007 & 10 years & $-5.19(1.39)$ & $<10^{-3}$ & $-9.71(1.26)$ & $<10^{-4}$ & - & - \\
\hline \multirow{2}{*}{ forest* } & 10 years & $0.19(3.66)$ & 0.96 & - & - & - & - \\
\hline & 3 years & $0.17(3.54)$ & 0.96 & - & - & $5.39(3.04)$ & 0.08 \\
\hline \multirow{2}{*}{ herbaceous* } & 10 years & $0.25(3.7)$ & 0.95 & - & - & - & $=$ \\
\hline & 3 years & $-0.39(3.52)$ & 0.91 & - & - & $53.61(3.24)$ & $<10^{-3}$ \\
\hline \multirow{2}{*}{ open water* } & 10 years & $0.32(4.84)$ & 0.95 & - & - & - & - \\
\hline & 3 years & $-2.69(4.79)$ & 0.57 & - & - & $0.52(6.15)$ & 0.93 \\
\hline \multirow{2}{*}{ shrub* } & 10 years & $-0.14(3.61)$ & 0.97 & - & - & - & $=$ \\
\hline & 3 years & $-0.8(3.48)$ & 0.82 & - & - & $33.73(3.1)$ & $<10^{-3}$ \\
\hline \multirow{2}{*}{ wetlands* } & 10 years & $0.55(4.27)$ & 0.90 & - & - & - & $=$ \\
\hline & 3 years & $-0.62(3.95)$ & 0.88 & - & - & $56.78(3.54)$ & $\leq 10^{-3}$ \\
\hline \multirow{2}{*}{ open } & 10 years & $0.02(0.01)$ & 0.21 & - & - & $0.02(0.01)$ & 0.09 \\
\hline & 3 years & $0.04(0.01)$ & 0.01 & - & - & $0.02(0.01)$ & 0.05 \\
\hline \multirow{2}{*}{ slope } & 10 years & $-0.01(0.03)$ & 0.66 & $-0.08(0.03)$ & $\underline{\underline{0.01}}$ & - & - \\
\hline & 3 years & $-0.08(0.03)$ & 0.02 & - & $\equiv$ & - & - \\
\hline \multirow{2}{*}{ rivers $* *$} & 10 years & - & 0.08 & - & - & - & - \\
\hline & 3 years & - & 0.84 & - & 0.23 & - & - \\
\hline \multirow{2}{*}{ elev** } & 10 years & - & $\underline{\underline{\underline{S 0.01}}}$ & - & - & - & 0.11 \\
\hline & 3 years & - & $\underline{\underline{\underline{0.10}}}$ & - & 0.27 & - & $<0.01$ \\
\hline \multirow{2}{*}{ roads $* *$} & 10 years & - & $<10^{-4}$ & - & $\mathbf{0 . 0 3}$ & - & $<10^{-3}$ \\
\hline & 3 years & - & $<0^{-3}$ & - & 0.04 & - & $<10^{-3}$ \\
\hline elk ** & 3 years & - & 0.57 & - & - & - & - \\
\hline
\end{tabular}




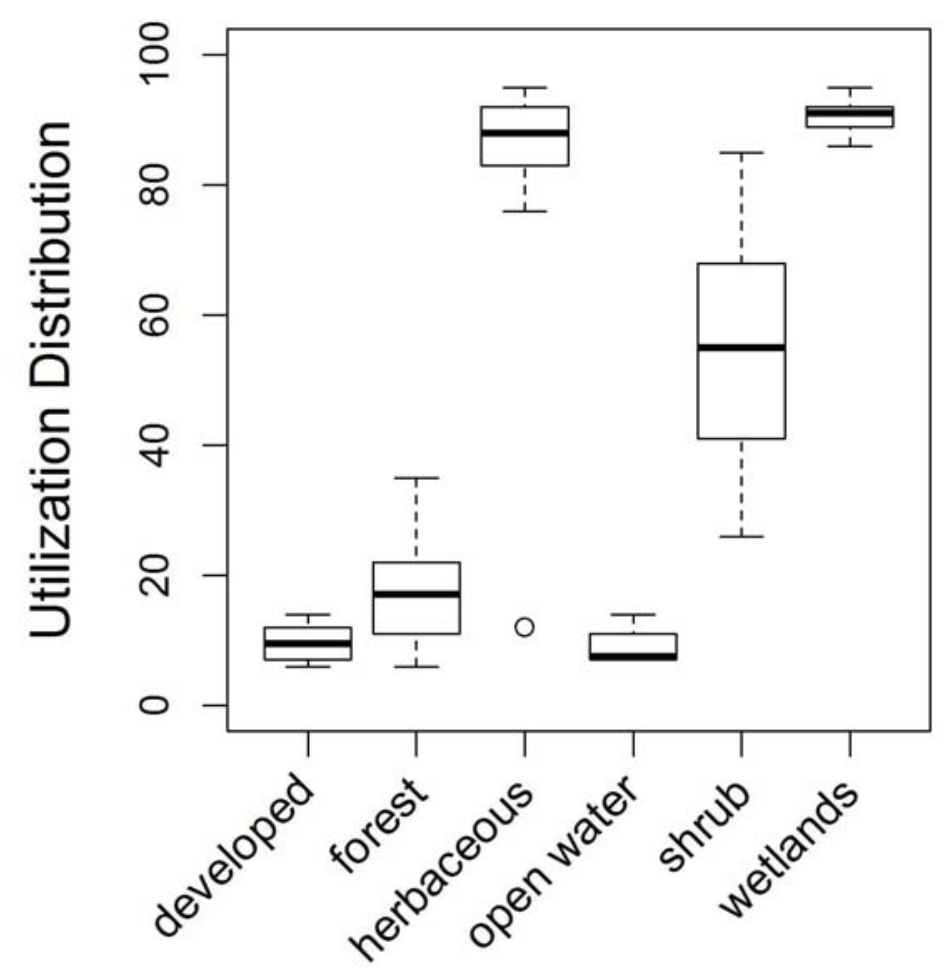

Figure 2.1. Habitat selection for different vegetation categories (x-axis) in early winter, for the 3-year data set (see Table 2.3). No preferences were detected in any other season or for the 10-year data set collected during early winter. Bold bars represent the median, boxes represent the interquartile range, and dotted lines extend to the range of observed data. The y-axis represents utilization distribution values. 

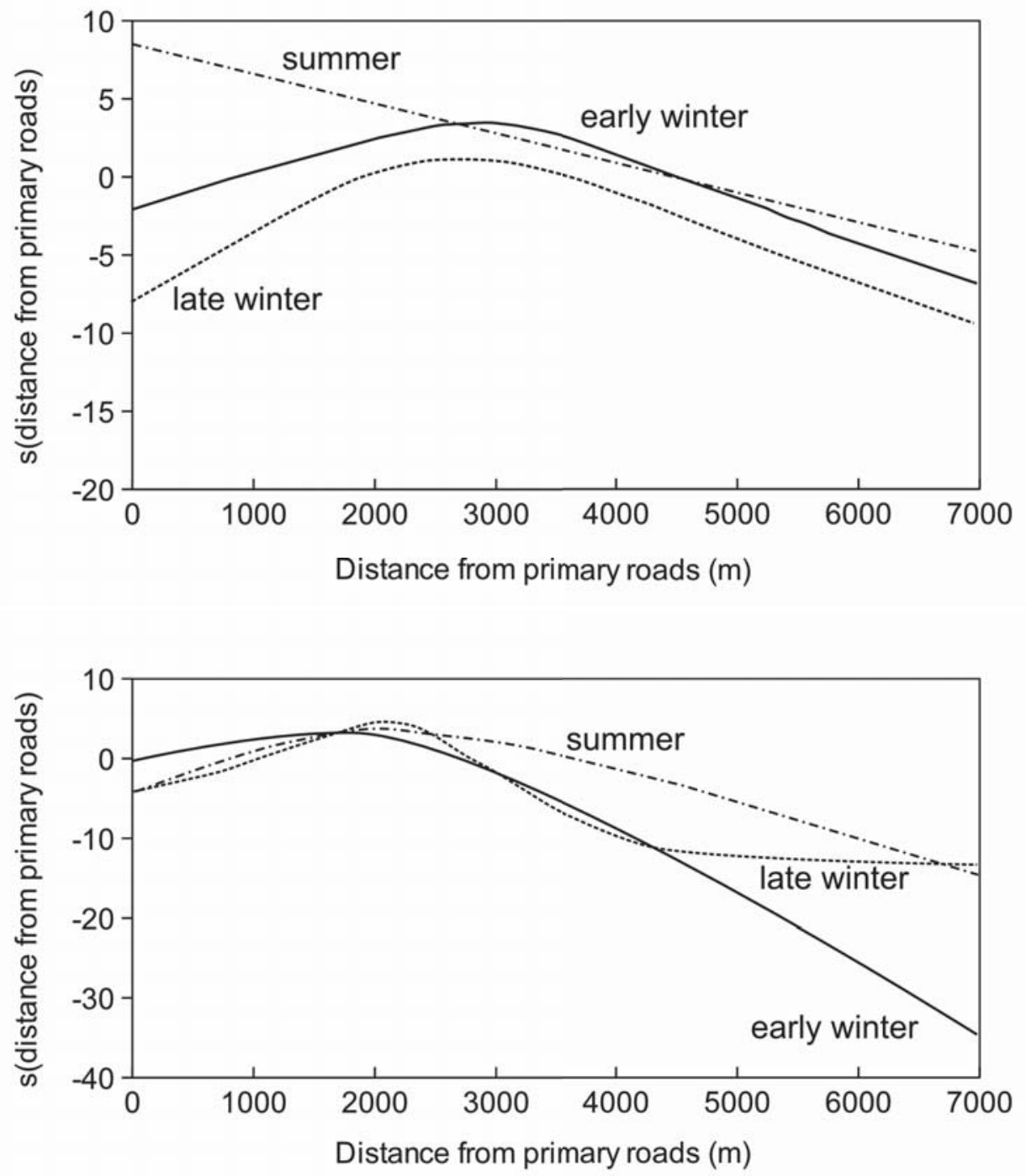

Figure 2.2. Smoothers representing wolf habitat selection related to distance from primary roads, for the 3-year data set (2000-2002, upper panel) and the 10-year data set (1998-2007, lower panel). For context, only 25\% of the Northern Range area is further than $7 \mathrm{~km}$ from primary roads. The y-axes represent a relative metric of preference. In the upper panel, p-values are $<10^{-3}$ (late winter), 0.04 (summer), and $<10^{-3}$ (early winter). In the lower panel, p-values are $<10^{-4}$ (late winter), 0.03 (summer), and $<10^{-3}$ (early winter). 

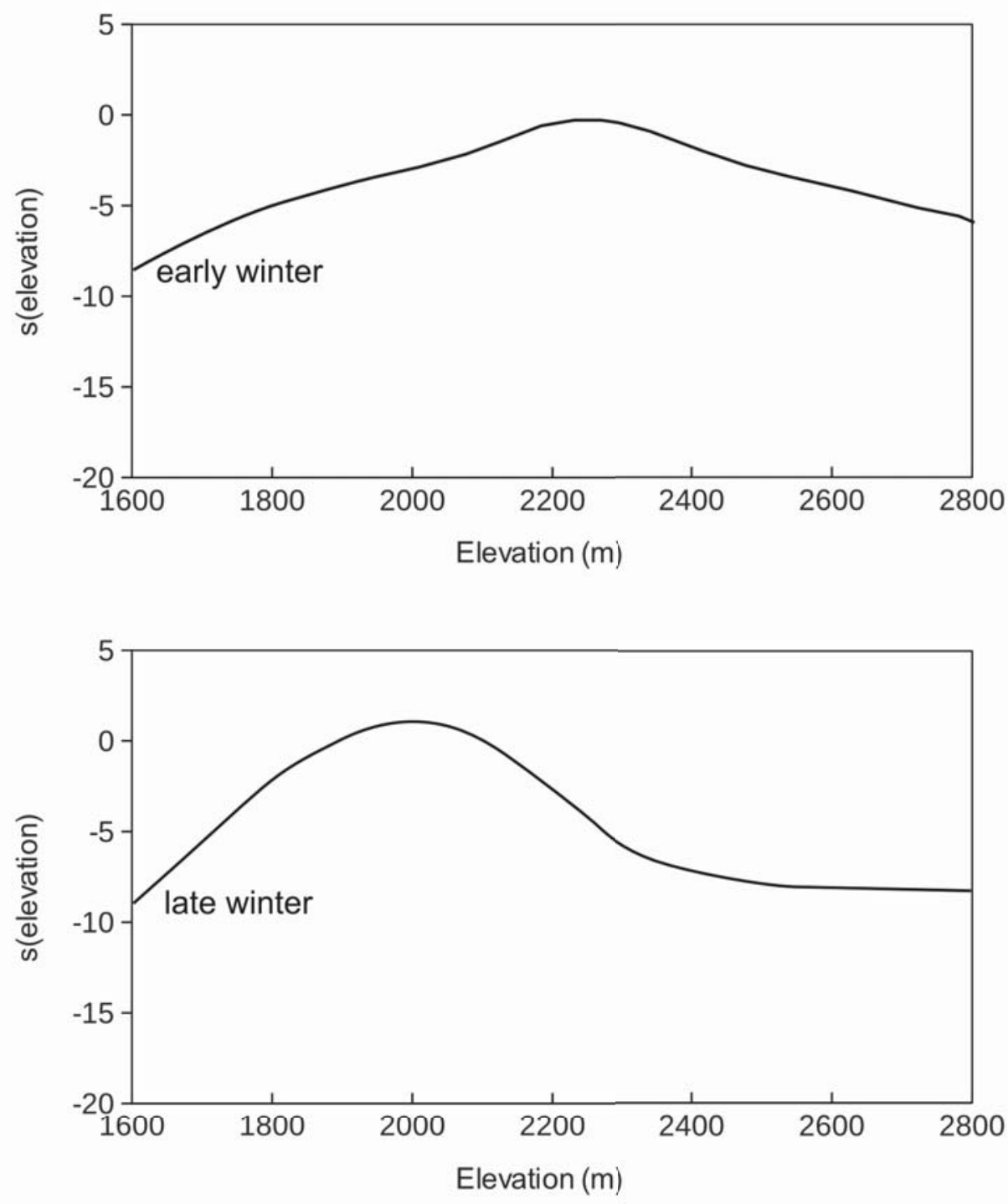

Figure 2.3. Smoothers representing wolf habitat selection related to elevation in early winter for the 3-year data set (2000-2002, upper panel) and in late winter for the 10-year data set (1998-2007, lower panel). Elevation was not a significant variable in any other season. The $y$-axes represent a relative metric of preference. P-values are $<0.01$ in both panels. 

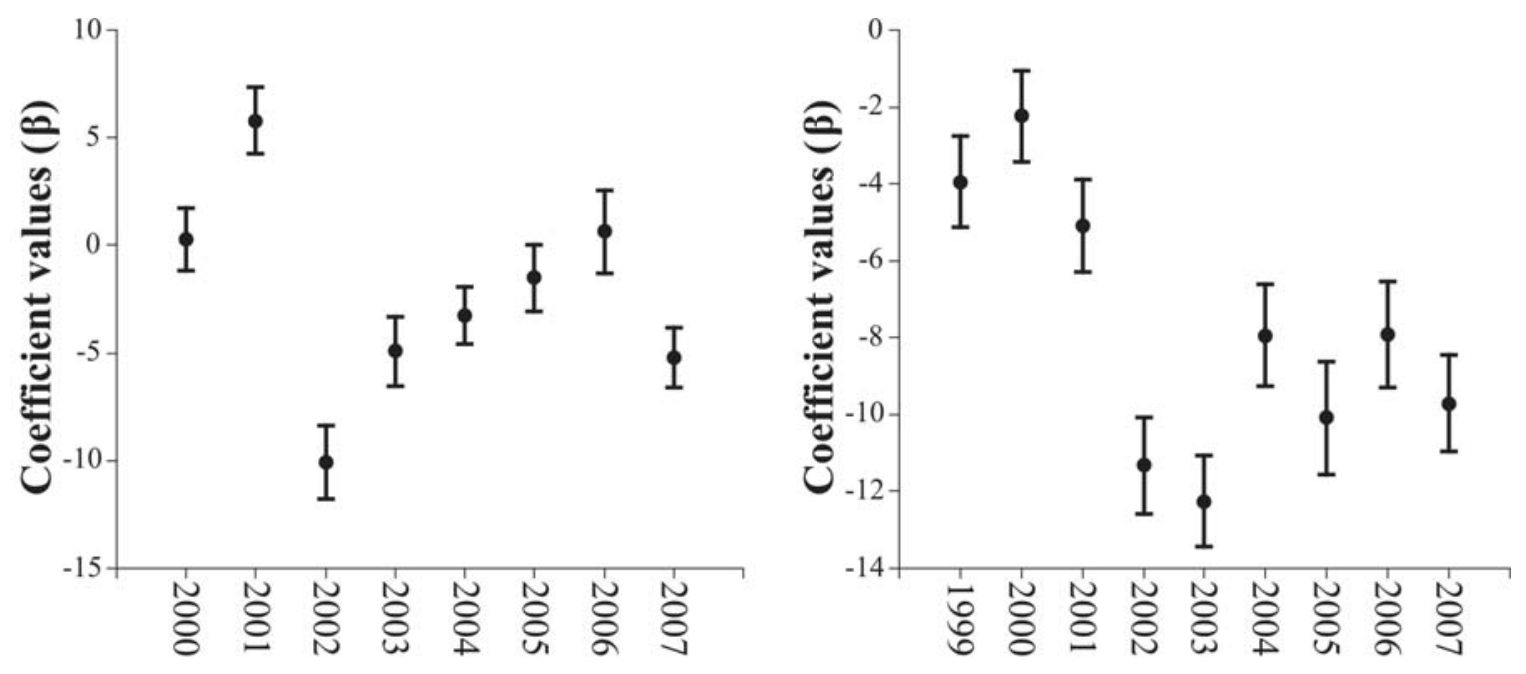

Figure 2.4. Coefficient values $(\beta)$ for the Year variable of models LW10 and S11 (see Table 2.2 and Table 2.3). Vertical bars represent standard errors. X-axis represents the Year. Left panel: late winter. Right panel: summer. 


\subsection{Supplementary Materials}

Spatial autocorrelation. - We were concerned about the potential bias that could result in our models from the spatial nature of our observations. A semivariogram of the residuals of our top models confirmed our concerns. We solved the autocorrelation problem by adding a spatial autocorrelation function to our best model (one for each season), with Pack as a grouping factor. The inclusion of that correlation function led to a better model for each season (Table 2.1). Using the corStruct set of functions available in $\mathrm{R}$ revealed that the summer data set contained three pairs of observations with the same spatial coordinates. Since the corStruct functions do not allow for zero distances between observations, we deleted one observation from each pair, leading to a reduced sample size of 1797 observations in the summer data set.

Variable coefficient models. - In our analysis, each variable coefficient model was based on data from all three seasons and included terms only for season and the continuous predictor variable of interest (e.g., roads or elev). With these terms and the by option in the $m g c v \mathrm{R}$ package, we calculated a p-value indicating whether additive terms differed between seasons. 


\section{USING INTERANNUAL VARIABILITY IN HABITAT USE TO BETTER UNDERSTAND HABITAT SELECTION IN WOLVES}

\subsection{Introduction}

Animal habitat selection is often context-specific and influenced by a variety of factors, including the availability of different kinds of habitat (Johnson 1980; Rachlow and Bowyer 1998; Martin 2001), the presence of competitors and predators (Larson 1980; Hughes et al. 1994; Rodríguez 1995; Creel et al. 2005; Fortin et al. 2005; Mao et al. 2005), and differences in habitat preference among individuals (Beyer et al. 2010). Since many of these factors are variable over time, we may observe variation in habitat use as well. The influence of these factors on habitat selection could be better understood by assessing whether or how interannual variation in habitat use by an animal covaries with temporally dynamic aspects of its environment. In other words, it would be interesting to know whether the habitat use of an animal varies from one year to another in a systematic manner with annual variation in, for example, climatic conditions. To date, such assessments are rare.

One strategy for such an assessment would be to use the volume of intersection (VI) index. The VI index can be used to quantify the overlap between two utilization distributions (UDs), which are probability density functions $\left(\hat{f}_{U D}(x, y)\right.$ at location $\left.[\mathrm{x}, \mathrm{y}]\right)$ that estimate the relative use that an individual has for every point within its home range (Seaman and Powell 1996). The VI index quantifies the overlap between the two UDs as:

$$
V I=\iint \hat{f}_{A}(x, y), \hat{f}_{B}(x, y) d x d y
$$

where $\hat{f}_{A}$ is one of the estimated UDs and $\hat{f}_{B}$ is the other (Seidel 1992; Millspaugh et al. 2004). The VI index not only accounts for the area of overlap between the two UDs, but also for how the two UDs overlap in terms of intensity of use. The VI index ranges from 0, representing no overlap, to 1, representing total overlap (Seidel 1992; Millspaugh et al. 2004). The VI index can be used to quantify the overlap between the UDs of neighboring individuals or the overlap between the UDs of a single individual estimated 
in different years, seasons, or times of the day. This approach has been used, for example, to conclude that home range use (UDs) varies considerably among seasons for Indian foxes and spotted skunks (Lesmeister et al. 2009; Vanak and Gompper 2010).

The goal of this study was to detect the influence of biotic and abiotic aspects of the environment on interannual variability in habitat selection. We used data from 15 wolf packs living in Yellowstone National Park between 1996 and 2008 to obtain 230 estimates of VI index, each estimate representing interannual variation in habitat use (based on season, see Assessing interannual variability). Our analysis began with a simple description of the overall amount of interannual variability in habitat use, as indexed by VI. Then, we evaluated whether variation in VI of a wolf pack is explained by interannual variability in climate (temperature, precipitation), properties of a pack (litter size, pack size, territory size, and changes in leadership), or biotic aspects of each pack's environment at a population level (wolf density, prey density, and ratio of wolves to prey). In the past, wolves have been described as habitat generalists that settle their territories where prey is abundant and human and competitor densities are low (Mladenoff et al. 1995; Mech and Boitani 2003; Oakleaf et al. 2006). For this reason, we expect wolf density, prey density, and ratio of wolves to prey to play a key role in shaping the interannual variability in wolf habitat selection. Pack-level properties are expected to be significant because of their role in the ecology of the species. Climate may be important in relation to its effects on wolf daily activities, such as travelling, resting or hunting.

To date, few studies have recognized temporal variation in habitat selection (e.g., Marks and Marks 1988; Zweifel-Schielly et al. 2009). None of them analyzed the direct relationship between variability in habitat selection and temporal changes of the environment. Here, we suggest using the VI index to identify which factors cause variability in habitat selection. This technique provided important insights into the processes that regulate habitat selection in a wide ranging species. 


\subsection{Study system}

Yellowstone National Park (YNP) is located in the central Rocky Mountains and has an area of $8,990 \mathrm{~km}^{2}$. The park is inhabited by a well-studied population of wolves (Yellowstone Wolf Project: Annual Reports). The wolf population is frequently represented as two subpopulations, one living on the Northern Range [1526 km2] and the other in the interior portion of the park [7,900 km2] (Figure 3.1). Elk are the dominant prey of Northern-Range wolves, while bison represent a larger share of diet for Interior wolves (Smith et al. 2004). During the study period (1996-2008), wolf density on the Northern Range varied from 13 to 64 wolves $/ 1000 \mathrm{~km}^{2}$ and from 2 to 9 wolves $/ 1000 \mathrm{~km}^{2}$ in the interior portion of the park.

Elevation in the park ranges between 1,500 and 3,500 meters. The dominant vegetative communities are steppe, shrub steppe, conifer forests, and aspen stands (Populus tremuloides) (Despain 1990). Winters are usually cold and snowy, while summers are dry. At lower elevations (northern portion of YNP), average annual precipitation is approximately $25 \mathrm{~cm}$, of which $30-35 \%$ is snow. Annual precipitation at higher elevations averages $180 \mathrm{~cm}$, primarily in form of snow (Farnes et al. 1999).

\subsection{Methods}

\subsubsection{Field methods and location data}

Between 1996 and 2008, we radiocollared wolves from each pack in YNP. Some wolves ( $n=289$ ) were outfitted with Very High Frequency collars (VHF; manufactured by Telonics, Inc. Mesa, AZ). Radiotelemetry locations were recorded from these wolves approximately on a weekly basis from January to September, with an effort to collect one location per day in March. Locations recorded from October to December were not enough to support the estimation of UDs. A different set of wolves $(n=34)$ was outfitted with downloadable Global Positioning System collars (GPS; manufactured by Televilt Lindesberg, Sweden, Telonics, Inc. Mesa, AZ, and Lotek, Newmarket, ON, Canada). These collars recorded locations every 30 minutes throughout the summer months and 
every 3 hours throughout the winter, during both day and night time. For additional details on the methods used to capture, handle, and locate wolves, see Metz et al. (2011).

We combined these two radiotelemetry data sets to estimate seasonal UDs of wolf packs in YNP. In order to make the two data sets comparable, we used GPS locations gathered only during daylight hours. To avoid autocorrelation among locations separated by short periods of time (Otis and White 1999), we culled the observations so that they included only a single location per pack per day throughout the winter (January - March). During the summer, packs are less cohesive and each pack is routinely characterized by small, semi-independent groups of wolves (Metz et al. 2011). Therefore, we considered these groups as the sample unit for the estimation of summer UDs (April - September). In other words, we randomly selected a single location per group per day. To perform this random culling, we used the extension Hawth's Analysis Tools for ArcGIS (Beyer 2004).

\subsubsection{Assessing interannual variability}

We quantified interannual variability in habitat use among packs during each of two seasons (summer [April-September] and winter [January-March]). Our first step in doing so was to calculate UDs for each wolf pack for each of these two seasons. We calculated the UDs using the fixed-kernel technique (Seaman and Powell 1996; Kernohan et al. 2001) with the "plug-in" method for bandwidth selection (Wand and Jones 1995; Gitzen et al. 2006), which is available in the "ks" library for R (R Development Core Team 2012). We eliminated the outer 5\% of the UDs, based on volume, to lower the risk of spurious results created by including low-use areas on the tails of the probability density function (Vanak and Gompper 2010). Because the fixed-kernel technique only gives reliable results if at least 30 locations are used, we limited our analysis to packs with more than 30 locations for any given season. Fifteen packs met this requirement (see Table 3.1). Next, we calculated the VI index for each pair of UDs belonging to each particular pack/year for each of the two seasons. We used two-way ANOVA to search for differences in mean VI between seasons (summer and winter) and between the two populations (Northern Range and Interior). 


\subsubsection{Regression Analyses}

To better understand if and how wolf habitat selection (represented by the VI index) is affected by biotic or abiotic features of the environment, we built and compared several regression models. We used data representing Northern Range wolves during summer and winter seasons.

Response variable. - The response variable for each regression model was $\mathrm{VI}_{\mathrm{i}, \mathrm{j}}$, where the subscripts $i$ and $j$ indicate that every VI index represents a difference in habitat use between two years, $i$ and $j$. By calculating VI in this manner, some observations will lack independence because they represent repeated measures of the same wolf pack. To account for any spuriousness that might arise from this circumstance, we also constructed mixed-effect models (see below). There is also a lack of independence that could result in a tendency for VI to decrease with an increase in the number of years that separate two estimates of UD. However, this concern is allayed by having observed no significant correlation between the VI indices and the number of years that separated the two UDs ( $p$ $=0.55)$.

Candidate predictors. - Candidate predictors included two climatic variables that were obtained from the National Biological Information Infrastructure project (http://www.nbii.gov, accessed August 2011). These variables were mean temperature $\left(\right.$ temp,${ }^{\circ} \mathrm{C}$ ) and mean precipitation (precip, $\mathrm{mm}$ ), both of which were specific to each season (summer and winter). We also considered three candidate predictors that represent population-level properties of the system: wolf number per squared kilometer, elk number per squared kilometer, and the ratio of wolves per elk. Moreover, we considered four candidate predictors that represent the year-specific properties of individual packs. They were litter size, $p k-s z$ (pack size), terr (per capita territory size, i.e., $\mathrm{km}^{2}$ divided by pack size), and changes in pack leadership. Because we used VI to quantify year-to-year changes in UDs, each candidate predictor was the absolute value of the difference between two years for that variable. In particular, leadership was the number of alpha wolves that were different between two years $(0,1$, or 2$)$. All of the ecological covariates 
were collected in the process of long-term monitoring of the Northern Range Yellowstone wolf population, see Smith et al. (2004) and Vucetich et al. (2011) for details. Elk counts are conducted in the YNP Northern Range only during the winter. Therefore, our summer regression models (see below) do not include elk and ratio as predictor variables. Packs were included in the regression analyses only if we had data for three or more summers or winters (see Table 3.1). Our data sets included a total of 6 packs per season. For some models (see below), we included the pack identity (pack ID) as a candidate predictor.

Summer regression analysis. - We built a set of regression models using an automated regression procedure from the "leaps" library of R. This algorithm uses forward stepwise regression to produce the most parsimonious (smallest Akaike's Information Criterion) univariate model, bivariate model, trivariate model, and so on. To compare the models constructed from this algorithm, we used p-values, $\mathrm{R}^{2}$, and Akaike's Information Criterion adjusted for small sample size $\left(\mathrm{AIC}_{\mathrm{c}}\right)$. For each one of our best models, we also searched for outliers and checked if any regression assumption was violated.

We implemented a model building strategy designed to first judge how the proportion of variation in summer VI could be explained by our candidate predictors without including pack ID as a predictor and then by considering possible individual pack differences by including pack ID. More precisely, we considered these models: (i) the models resulting from the automated procedure where all candidate predictors were considered, except pack ID, (ii) the best model resulting from the automated procedure where the candidate predictors were those left in the best-performing model in step (i), in addition to pack ID (treated as a fixed effect), and (iii) a model that included only pack ID (as a fixed effect).

By treating pack ID as a fixed effect, we can assess the portion of variation attributable to pack ID and compare the $\mathrm{R}^{2}$ of models that do and do not include pack ID. Treating pack ID as a fixed effect is sensible insomuch as our interest is to explain variation that has already been observed in VI (i.e., among the packs that were actually observed). However, it is also useful to ask: What is the expected influence of candidate 
predictor variables (like temp and wolf), given that our sample of packs is randomly selected from among all the packs that could, in principle, have been observed? To make this assessment, we built a model that treated pack ID as a random effect. More precisely, we considered the model that resulted from step (ii) and built an analogous model containing those same predictors, except we treated pack $I D$ as a random, rather than a fixed, effect. That is, the model without a random effect estimated separate intercepts for each pack, while the model with random effects estimated only the variance of the intercepts that characterized each pack, rather than estimating the intercepts themselves. Our interest in building this mixed-effect model was to assess whether the coefficients and p-values associated with potentially important predictors were substantively affected by treating pack ID as a random effect, as sometimes can be the case (Zuur et al. 2009).

Winter regression analysis. - Due to the smaller sample size of data collected during the winter season $(\mathrm{n}=55)$, the steps performed in the summer analysis could not be applied directly to the winter data set. Instead, we developed four separate sets of models aimed to understand whether or how VI is influenced by climate, properties of a pack, and properties of the population. In particular, Model (A) included only climate variables as predictors (temp and precip), Model (B) included only pack-level properties (i.e. terr, leadership, and $p k-s z$ ), Model (C) included only population-level properties (i.e. wolf, elk, and ratio), Model (D) included only pack ID, and Model (E) included only the predictors found to be significant from the previous four models. We also built a model that included the same fixed effects that were included in Model (E), but also pack ID as a random effect. We did not consider litter as a candidate predictor in the winter models, because young wolves can disperse from their natal pack starting in January of their first year (Fuller 1989; Gese and Mech 1991) and precise counts of pups were not available for the winter season (January-March). 


\subsection{Results}

The goals of our study were to i) quantify interannual variability in wolf habitat selection, ii) assess if this variability is explained by differences among seasons or areas where a pack lives, and iii) verify if and how this variability is influenced by changes in the environment that surrounds a wolf pack.

Overall, VI was highly variable (Figure 3.2). The interquartile range was [0.41, 0.59] and the coefficient of variation was $30.6 \%$. A small but statistically significant portion of the observed variation was attributable to differences between seasons ( $n=230$, pvalue $=6 \times 10^{-3}$, two-way analysis of variance, Figure 3.3a) and differences based on the area of the park where a wolf pack lives $\left(n=230, p\right.$-value $=2.1 \times 10^{-3}$, Figure $\left.3.3 \mathrm{~b}\right)$. The mean VI was slightly greater during the winter and for Northern Range wolf packs. In other words, wolf habitat use varied less from year to year in winters and in the Northern Range of YNP (compared to the interior of the park).

Next, we verified what other factors could explain the observed variability in VI, dividing our analysis into two seasons (summer and winter). When VI was considered during the summer season, and when pack identity was excluded as a potential predictor, the best model explained $12 \%$ of the variation in VI and included pk-sz, litter, temp, and leadership as predictors (see Model 4 in Table 3.2). Pack ID, as a fixed effect, explained $43 \%$ of the variation in VI by itself (Model 8; Figure 3.4). When pack ID and other variables were both considered at the same time to be candidate predictors, the most parsimonious model explained $48 \%$ of the variation in VI (Model 9). Most of the variation in this model was accounted for by pack ID (Figure 3.4 and Figure 3.5, left panel). There was also a small, but statistically significant tendency for VI to increase between years with greater differences in litter and leadership (Figure 3.5, left panel, and Figure 3.6a,b). The residuals for this model did not show signs of non-normality, heterogeneity, or any outliers. To summarize, pack identity was the most important predictor of the variability in VI during the summer, followed by changes in litter size and leadership of a pack. We also build Model 10 to verify if treating pack ID as a random effect (but otherwise including the same predictors of Model 9) improved our 
model performance. On the contrary, Model 10 (Table 3.2) had a much lower parsimony compared to Model $9\left(\Delta \mathrm{AIC}_{\mathrm{c}}=34.02\right)$. Moreover, the sign and magnitude of the coefficients for the mixed-effect model were very similar to those produced by treating pack ID as a fixed effect. In particular, the regression coefficients for these models differed by less than $3 \%$ (see Figure 3.7). These results suggest that the models treating pack ID as a fixed effect are not misleading.

Of the models that we developed to explain variation in winter VI, the best model (E) explained $34 \%$ of the variation in VI and indicated that VI between two years tended to be greater when there were greater differences in pack size $\left(\mathrm{p}=<10^{-3}\right)$ and precipitation $\left(\mathrm{p}=<10^{-3}\right)$ (Table 3.3; Figure 3.5, right panel, and Figure 3.6c,d). The residuals for this model did not show signs of non-normality, heterogeneity, or any outliers. Importantly, pack ID was not an important consideration, as a fixed or random effect, for explaining variation in winter VI (Table 3.3). Model (C) is also important for demonstrating the inability to predict VI from variables that one might expect to be important (i.e., elk, wolf, and ratio). These predictors were not only statistically insignificant, they were also sufficiently independent from one another to allay concerns about collinearity (i.e., the variance inflation factors for this model were <3.5). 


\subsection{Discussion}

Relatively few studies have used the volume of intersection (VI) index to study habitat related-behaviors. To our knowledge, none have used it to explain temporal dynamics in habitat selection. For this reason, there is value in reflecting on some basic observations from the sample of VI estimates that we observed. For the 15 wolf packs that we studied over a 13-year period, the overall mean value of VI was 0.49 (Figure 3.2). This value means that there was, on average, an approximately 50\% overlap between UDs calculated in two different years. In other words, the patterns of habitat use by a wolf pack inside its territory changed from one year to another by approximately $50 \%$. Because 0.49 (the mean value of VI we observed) is the midpoint between 0 and 1 (the possible range of values for VI), one could be just as impressed by the temporal stability in habitat use or the temporal variability. We could state that, to some extent, wolves vary considerably their habitat use from one year to another, but at the same time they repeatedly use some areas of their territory. Moreover, the distribution of VI was itself variable, with approximately $20 \%$ of values being greater than 0.7 or less than 0.3 (Figure 3.2). That is, it was not uncommon to observe considerable overlap or very little overlap between UDs. The values of VI were not associated with the period of time separating two UDs, suggesting that temporal dynamics in habitat-related behavior did not fluctuate in a gradual, auto-correlated manner.

Our results show that habitat use by wolves at a territory level is partly stable and partly variable. The aspect of habitat selection that is temporally stable may be attributable to characteristics of the environment that are stable from year-to-year, such as elevation, slope, aspect, roads, rivers, or vegetation types. Conversely, the temporally dynamic facets of habitat selection may be attributable to biotic or abiotic aspects of the environment that change over time (discussed below). A great deal of habitat research focuses on assessing the influence of static aspects of the environment to explain habitat selection (e.g., Paquet et al. 1996; Ciucci et al. 2003; Arjo and Pletscher 2004; Oakleaf et al. 2006; Eriksen et al. 2009). Our study highlights that $50 \%$ of the interannual variability 
in habitat use is caused by dynamic aspects of the environment. For wolves, these features change depending on the season.

During summer, a large portion of variation in VI (42\%) was attributable to consistent differences in habitat use among the different packs that lived in the Northern Range of YNP (Figure 3.4 and Figure 3.5, left panel). These differences could be attributable to unobserved differences between territories in static characteristics of environment (Milakovic et al. 2011) and (or) to differences in the behavior of the wolves leading each pack. This explanation was confirmed by our finding that overlap in habitat use also had a slight tendency to decline with increasing differences in the leadership of a pack (Figure 3.6b). Even though this relationship accounted for only a small portion of the total variability in summer VI, it was statistically significant (Figure 3.5, left panel). The relationship between VI and leadership and pack identity suggests that behaviors learned through habituation and perhaps some higher order learning process account for important differences in habitat selection among packs. Dissimilarities in behavior among individual animals are referred to as personality (Dall et al. 2004; Biro and Stamps 2008; Biro and Dingemanse 2009), and consistent differences in learned behavior among groups of social animals are referred to as culture (Heyes and Galef Jr 1996). Animal personality and culture have an important influence on a number of behaviors that influence population dynamics (Camperio Ciani et al. 2007; Cote et al. 2010). Our results suggest that personality and culture may also influence habitat-related behaviors.

Moreover, overlap in summer habitat use between years had a slight tendency to decline with increasing differences in litter size (Figure 3.6a), but not pack size. This suggests that the habitat use differences were driven by a pack's need to find rendezvous sites that can accommodate different numbers of pups, or some other aspects of pup rearing; but not so much by the increased need for food that larger packs experience. In any case, the influence of litter size was small (Figure 3.5, left panel).

In summer, pup rearing, personality, and culture seem to be the most important factors influencing interannual variability in habitat use. Instead, precipitation and pack size play a key role in these processes in winter. Interannual overlap in habitat use had a tendency to decline with increasing differences in pack size (Figure 3.6c) and precipitation, which 
falls as snow (Figure 3.6d). The relationship with snow likely reflects the tendency for wolves and their prey to concentrate more in lower elevation habitats during years with increased snowfall, which tends to make higher elevation habitat unavailable to them. In particular, wolves may avoid areas with deep snow cover both to make locomotion easier (Paquet et al. 1996; Ciucci et al. 2003) and to enhance their hunting success, given that prey are more vulnerable to predators in areas of deep snow (discussed in Mao et al. 2005). The relationship with pack size likely reflects larger packs' need to kill larger numbers of prey. If a larger number of prey is required, a pack may have to utilize less productive hunting grounds in addition to prime hunting grounds. Similarly, a larger pack may have available to it (by virtue of its size) a greater diversity of hunting strategies, allowing it to successfully hunt in habitats where smaller packs would fail. A larger pack may also be more successful in defending its territory (Mech and Boitani 2003). Therefore, the pack may be able to control the best quality areas of its territory more consistently in years with larger pack size.

Contrary to our expectations, VI was never associated with any of the population-level properties we assessed. Elk density, the ratio of wolves per elk, and wolf density represent population-level estimates of prey availability and intraspecific competition. While these variables are essential for understanding wolf population dynamics, they appear to be considerably less important for determining dynamics in habitat selection. Historically, the best wolf habitat has been simply considered the one with higher prey abundance (Mladenoff et al. 1995; Corsi et al. 1999; Mladenoff et al. 1999; Oakleaf et al. 2006). However, other findings suggest that predators prefer locations where prey are more likely to be found and killed, not necessarily where they are most abundant (Hopcraft et al. 2005; Balme et al. 2007; Milakovic et al. 2011). The same may be the case for wolves. At the territory level, wolves might select habitats where it is easier to encounter and (or) kill a prey, rather than where prey is more abundant. Rich et al. (2012) found, for example, that wolf territory size is not correlated with prey biomass and hypothesized that prey availability and vulnerability may be more important in shaping wolf distribution, rather than absolute biomass. Similar patterns may lie behind wolf 
habitat selection. Finally, it remains likely that intraspecific competition has an important influence that is not captured by the metrics used in this study.

When we assessed if some of the variability in habitat use (i.e., in VI) could be explained by differences in the areas where wolves live, we found that VI was slightly greater for wolves living on the Northern Range than it was for wolves living in the park's interior (Figure 3.3b). The difference we observed between the two wolf populations may be explained by the Northern Range being a smaller and more stable ecosystem compared to the interior portion of the park. In fact, in the Northern Range elk are available to the wolf population year around (Smith et al. 2004). Whatever the cause for this difference is, this result is interesting because it shows that variation in habitat use may differ among different populations of the same species, even if they live in neighboring areas.

Habitat research has tended not to appreciate the relevance of temporal variation in habitat selection. This is in large part because most habitat research rarely spans enough time to observe temporal variability. We used the Web of Science to identify all papers with keywords "RSF", "RUF", "compositional analysis", and "habitat selection", published between 2002 and 2012 in the journals Ecology, Journal of Animal Ecology, Oikos, and Journal of Wildlife Management. Of the twenty-six papers identified, half of them observed habitat behaviors for three or fewer years, and 25 of the 26 papers observed habitat behaviors for 7 or fewer years. Our study underlines that temporal variation is an important component of habitat selection and therefore should be taken into consideration when studying these processes.

Even though we identified several factors that explained part of the temporal variation in habitat-related behavior, half of the variation in that dynamic was not explained by any of the aspects we considered (Figure 3.5). The prospects for improving our understanding of temporal variation in habitat selection are exciting. Our results should provide the motivation to meet the challenge of collecting the long-term data necessary for such assessments. 
Table 3.1. Number of seasons (divided by pack) for which we had sufficient sample size to estimate Utilization Distributions. Only one estimate of VI was available for the Geode Creek and Oxbow Creek packs in the summer and for Oxbow Creek and Slough Creek packs in the winter. Therefore, these packs were excluded from the regression analyses.

\begin{tabular}{|c|c|c|}
\hline Northern Range packs & \# of summers & \# of winters \\
\hline Agate Creek & 4 & 3 \\
\hline Druid Peak & 9 & 6 \\
\hline Geode Creek & 2 & 3 \\
\hline Leopold & 9 & 8 \\
\hline Oxbow Creek & 2 & 2 \\
\hline Rose Creek & 5 & 3 \\
\hline Slough Creek & 5 & 2 \\
\hline Swan Lake & 4 & 3 \\
\hline Interior packs & \# of summers & \# of winters \\
\hline Chief Joseph & 6 & 0 \\
\hline Cougar Creek & 4 & 0 \\
\hline Crystal Creek & 4 & 0 \\
\hline Gibbon Meadows & 2 & 0 \\
\hline Mollie's & 5 & 2 \\
\hline Nez Perce & 7 & 4 \\
\hline Yellowstone Delta & 0 & 2 \\
\hline
\end{tabular}




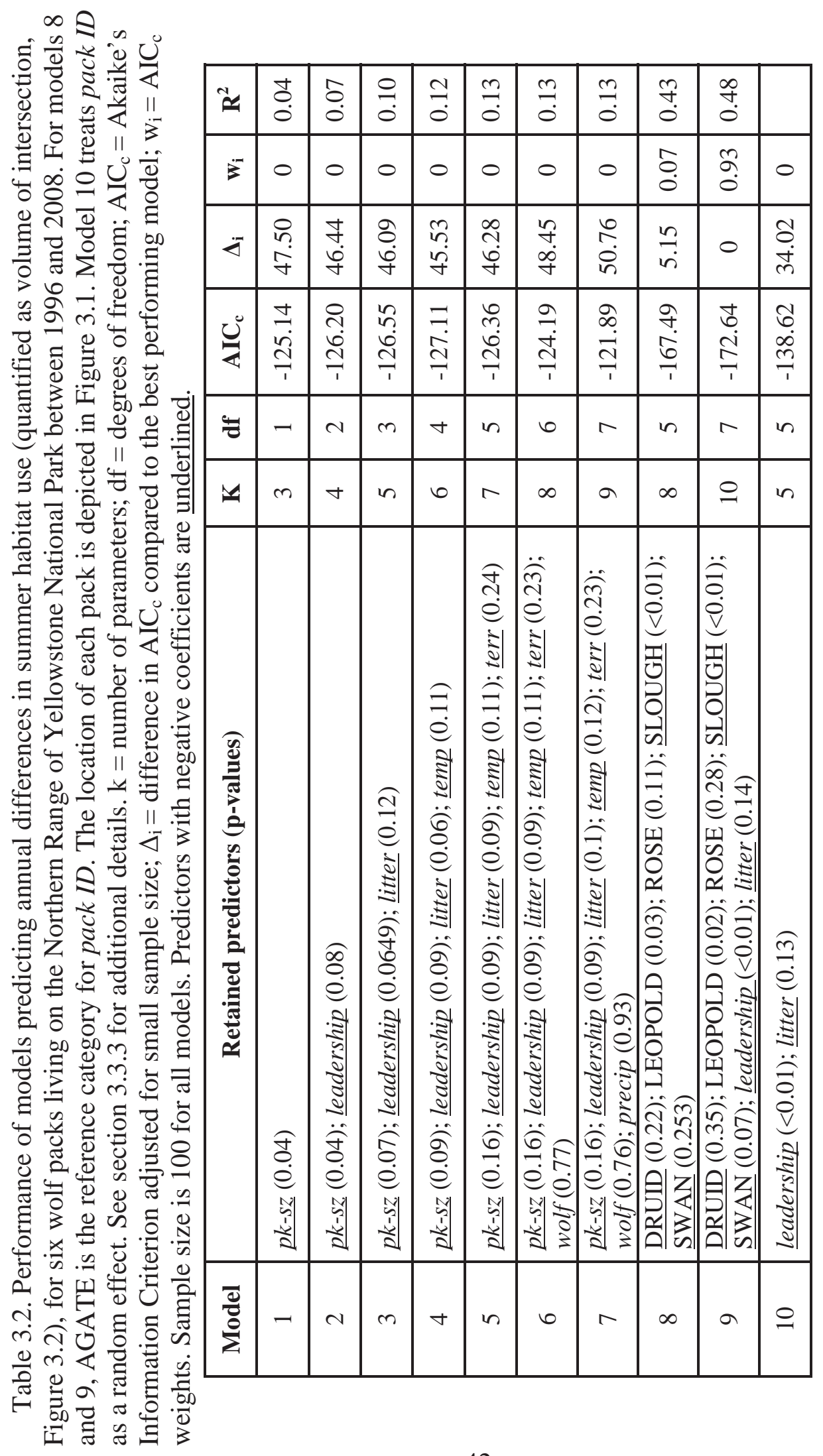




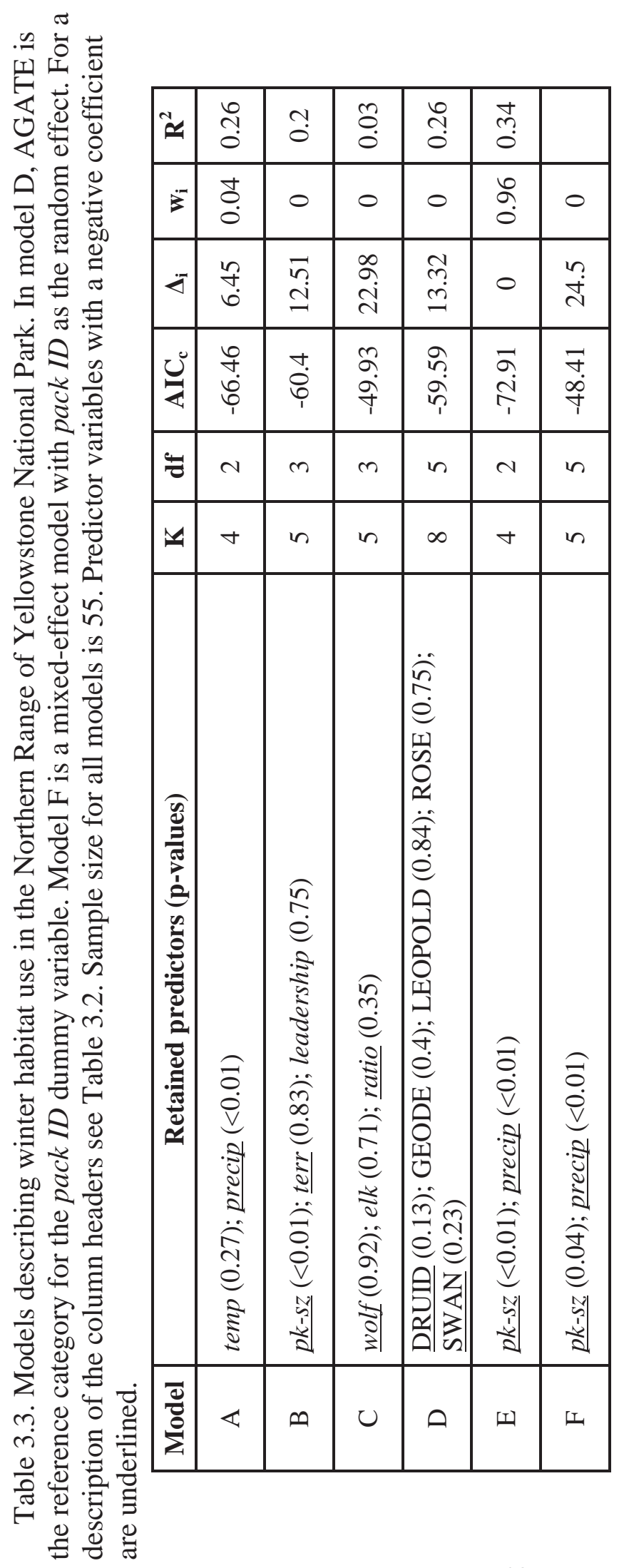




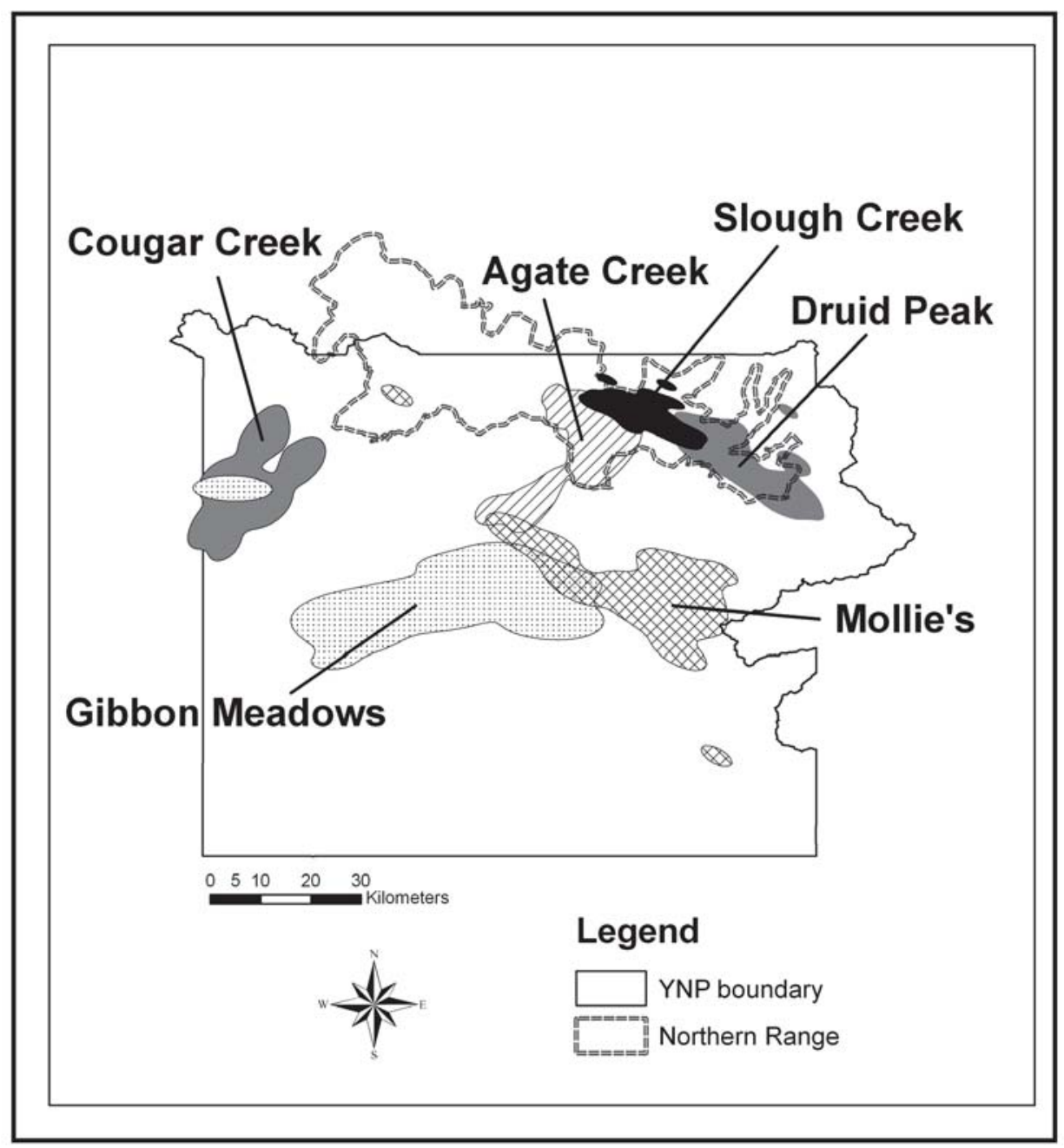

Figure 3.1. Territory boundaries of 6 packs living in Yellowstone National Park in summer 2008. Agate Creek, Druid Peak, and Slough Creek packs belonged to the Northern Range population. Cougar Creek, Gibbon Meadows, and Mollie's were considered Interior packs. 


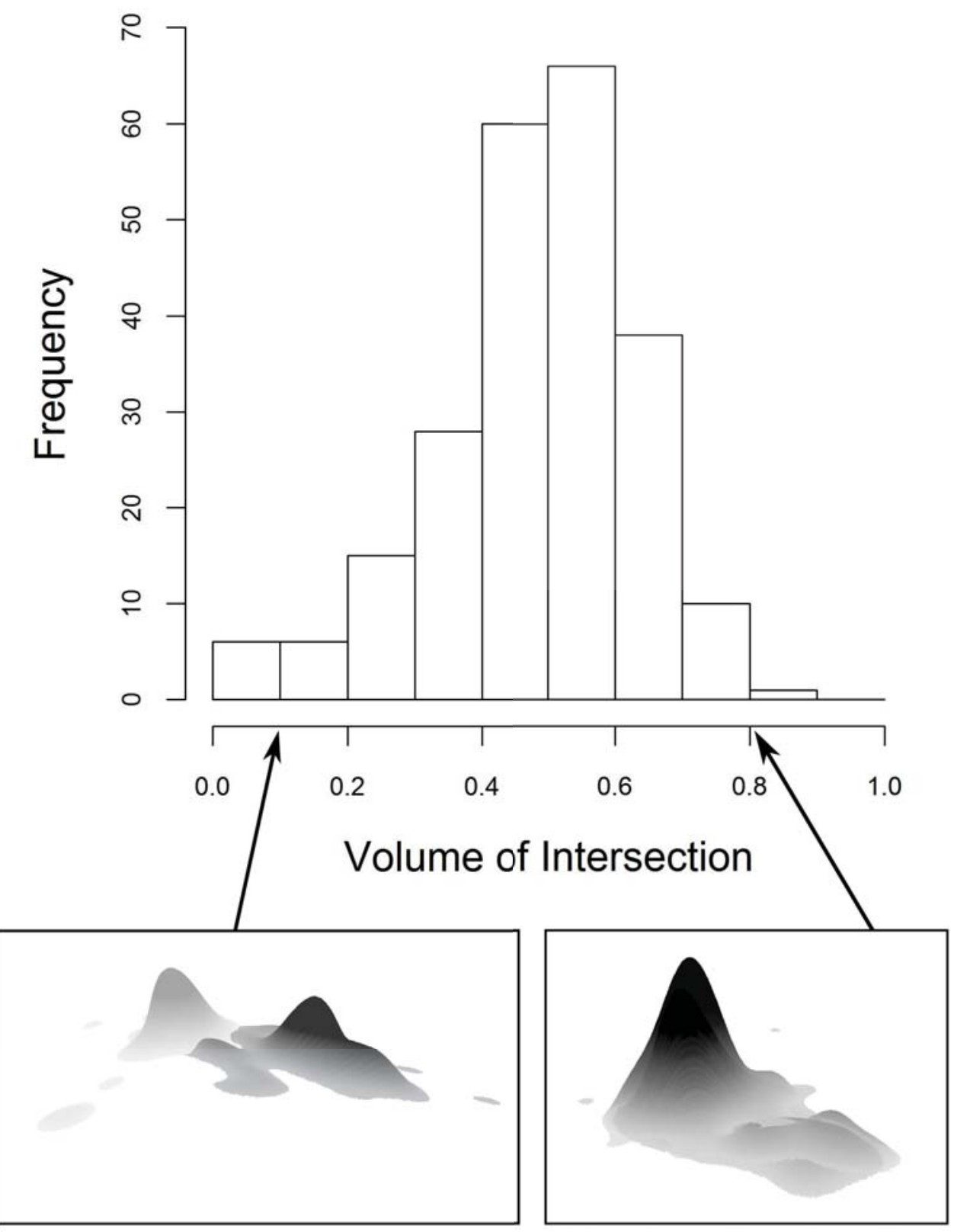

Figure 3.2. Frequency distribution of volume of intersection for 15 packs living in Yellowstone National Park between 1996 and 2008. Each estimated volume of intersection represents the overlap of territory use for a particular pack during a particular season (summer or winter) between two years. The lower left panel represents an example of two overlapping UDs with VI $=0.09$. On the bottom right, two overlapping UDs with VI $=0.81$. 
a)

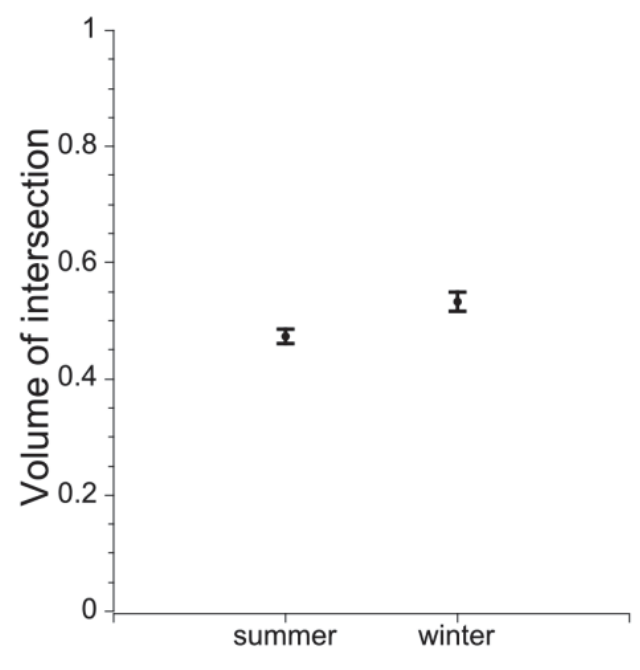

b)

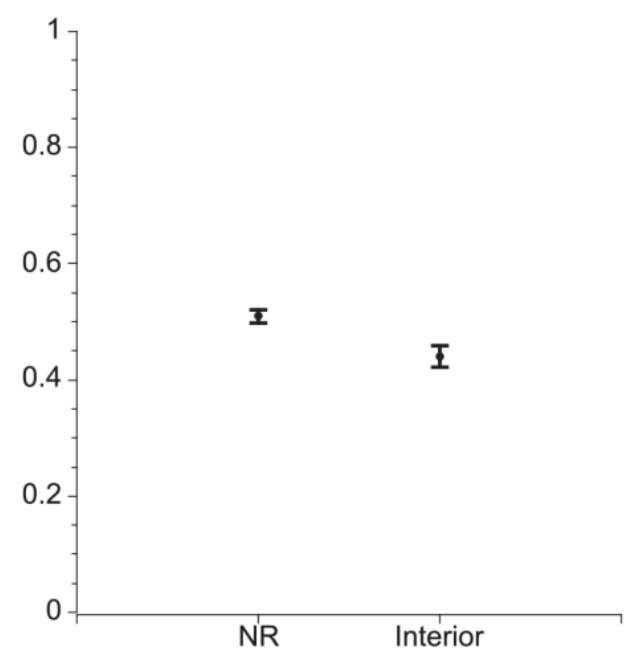

Figure 3.3. Mean volume of intersection for wolf packs living in Yellowstone National Park (both Northern Range and Interior) during the summer and winter (a), and for wolf packs living on the Northern Range and in the Interior (both seasons) (b). Vertical bars represent standard errors. Both panel depict statistically significant differences (pvalue $=0.0065$ for panel (a) and $p$-value $=0.0243$ for panel (b)) . 


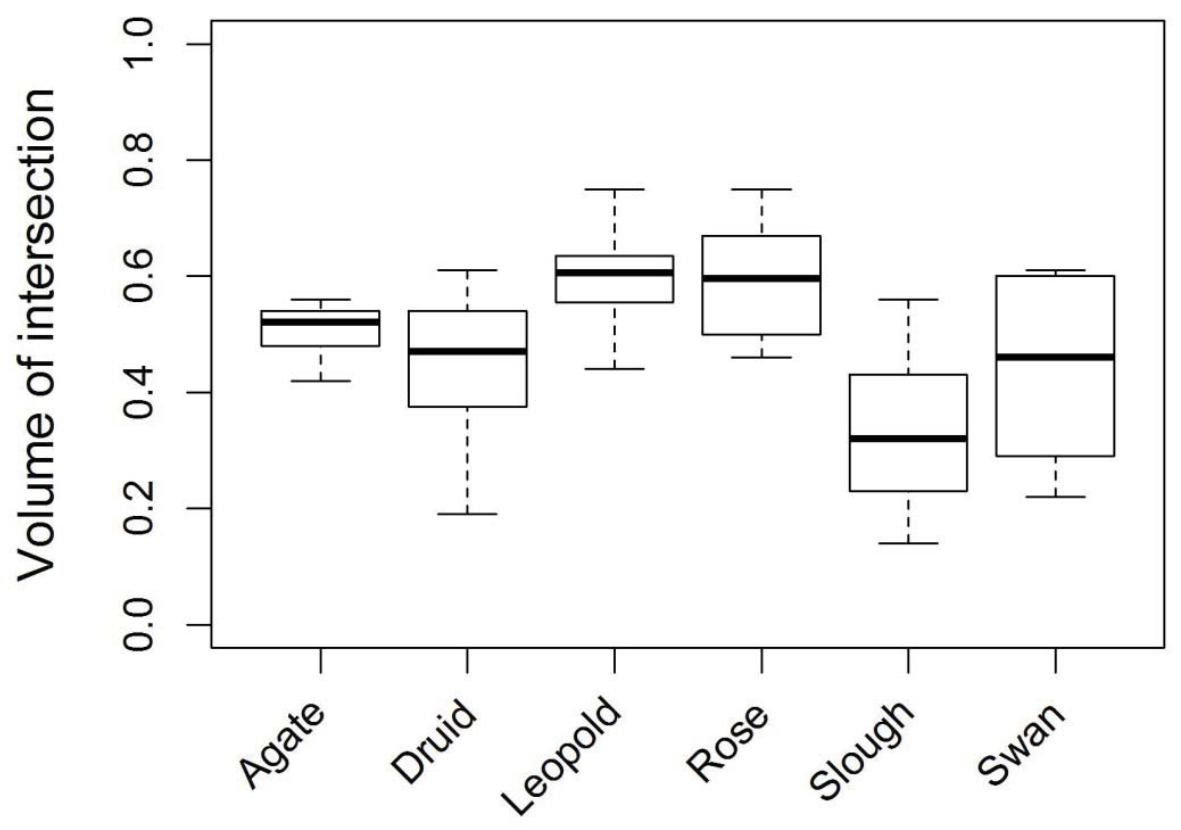

Figure 3.4. Volume of intersection for summer territory usage for packs living on the Northern Range of YNP. The best performing models for summer volume of intersection (Table 3.2) suggest that volume of intersection varies significantly among packs. We were unable to attribute these differences to any particular difference in quality of each pack's habitat (e.g., mean elevation, territory size, etc.). Bold bars represent the median, boxes represent the interquartile range, and dotted lines extend to the range of observed data. 


\section{Summer}

Pack ID, $42 \%$

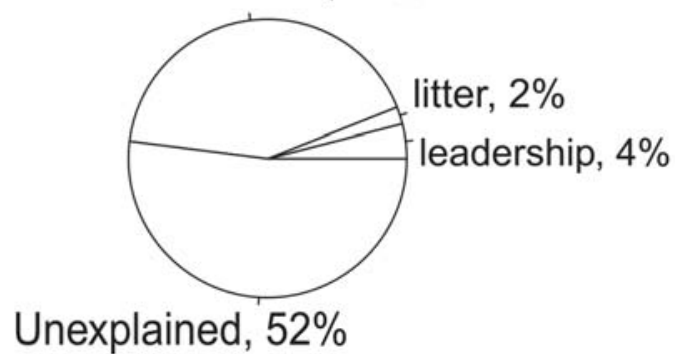

Winter

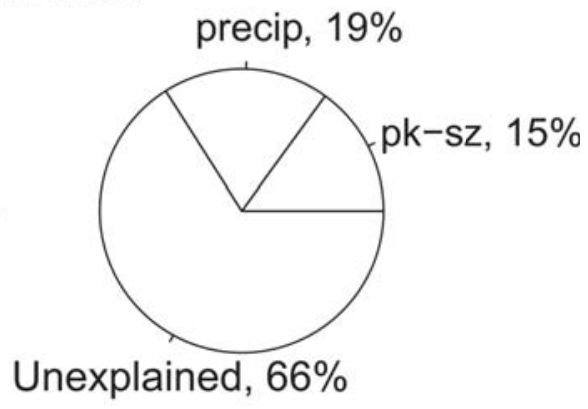

Figure 3.5. The proportion of variance in volume of intersection explained by various predictors according to the best performing model during summer (left panel; Model 9 in Table 3.2) and winter (right panel; model $\mathrm{E}$ in Table 3.3). The proportion of variance described by a predictor is obtained by multiplying the standardized regression coefficient for the predictor by the correlation coefficient between the predictor and volume of intersection (Schumacker and Lomax 2004). For details on the meaning of each coefficient label see section 3.3.3, Candidate predictors. 
a)

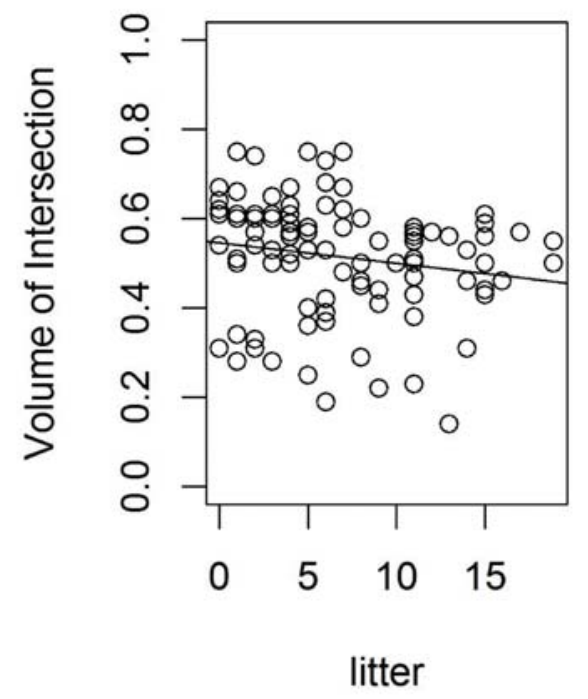

c)

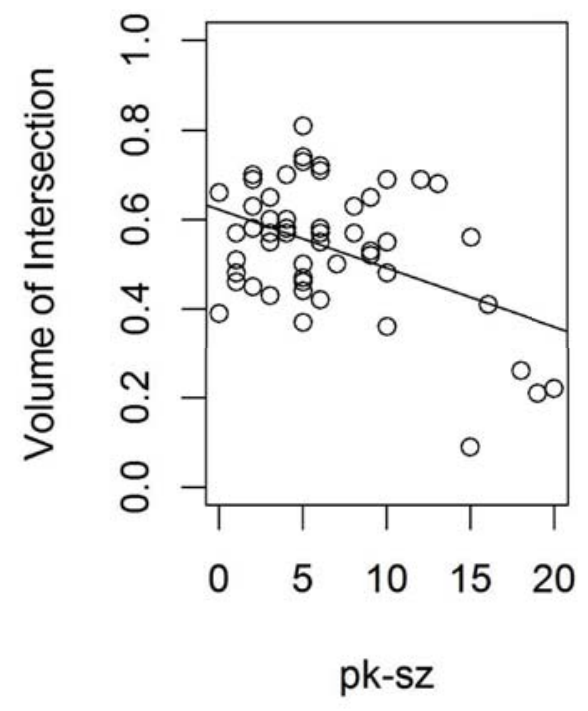

b)

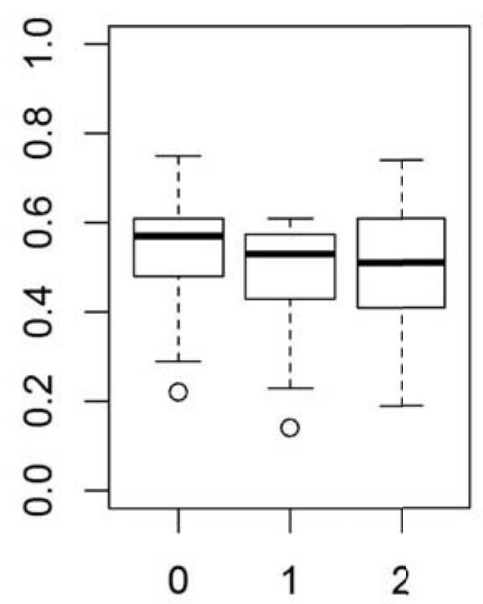

leadership

d)

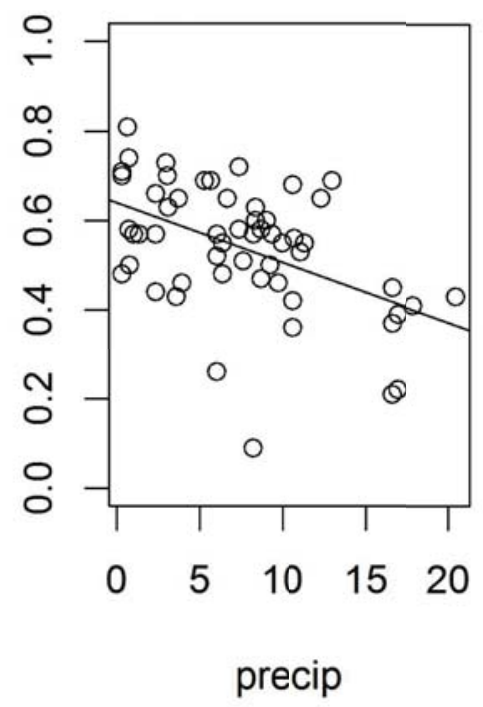

Figure 3.6. Relationship between volume of intersection index (VI) and predictor variables: a) litter size; b) leadership; c) pack size; d) precipitation. In panels a), c), and d), dots represent data points and the black line is the regression line linking the two variables. In panel $b$ ), each boxplot represents one leadership category: $0=$ no changes in leadership, $1=$ one different alpha wolf between the two years represented by VI, $2=$ both alpha wolves changed. Panels a) and b) are for Model 9 (Table 3.2); panels c) and d) are for Model E (Table 3.3). 


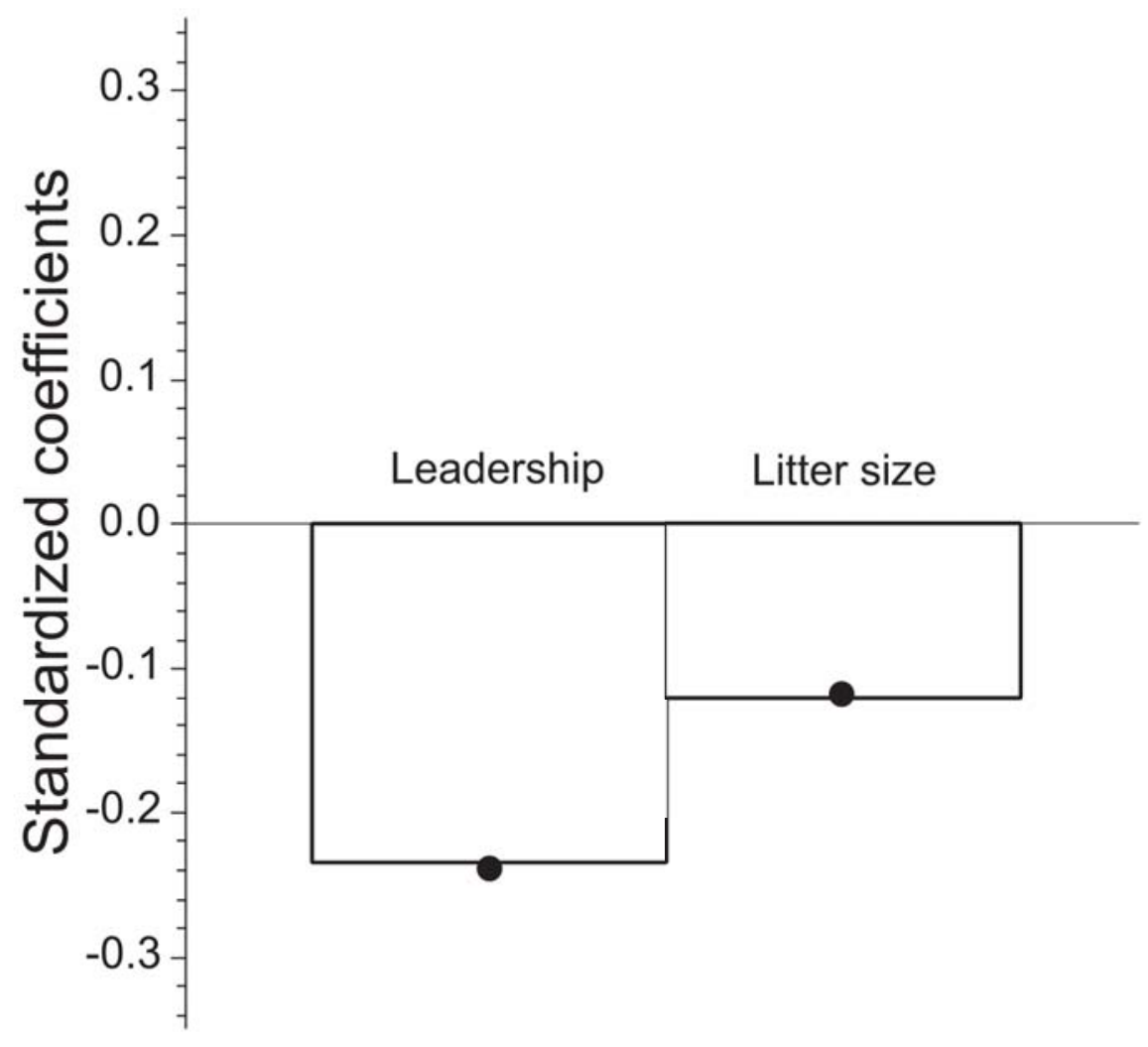

Figure 3.7. Standardized regression coefficients for two models, each aiming to predict the volume of intersection in summer. Bars depict coefficients from the best performing model (Model 9 in Table 3.3), which is a fixed-effect model. Dots represent coefficients for Model 10, an analogous model containing the same fixed effects, except that Pack ID is treated as a random effect. The similarity in coefficients between the two models suggests that estimates of coefficients are not appreciably affected by treating Pack ID as a random effect. For details on the meaning of each coefficient label see section 3.3.3, Candidate Predictors. 


\section{THE INFLUENCE OF HABITAT SELECTION ON WOLF REPRODUCTIVE SUCCESS}

\subsection{Introduction}

Once an animal reaches sexual maturity, surviving and successfully reproducing become the two mains goals in the animal's life. All the choices that the animal makes are meant to minimize the risk of dying and maximize the number of offspring that will reach independence, i.e. its reproductive success.

An animal's reproductive success can be affected by several factors, such as age (Arlt and Pärt 2007; Rebke et al. 2010), body size (Clutton-Brock 1988), and social status (Mech and Boitani 2003). Habitat selection is also an important aspect in determining if an animal and its offspring will survive. Food quality and protection from predators, competitors, and adverse weather conditions are elements that influence the individual's choice of habitat and therefore its survival.

Animals should select habitats that enhance their chance of surviving and producing the highest possible number of offspring (Levins 1968; Orians 1980; Arlt and Pärt 2007). Individuals that select better quality habitats are expected to have a higher reproductive success (McLoughlin et al. 2006). Therefore, reproductive success can be used as an index of habitat quality (Van Horne 1983). Often, researchers analyze habitat selection and come to the conclusion that the habitat selected by a species is also the one that provides the highest reproductive success, i.e. the best quality habitat. Nevertheless, useavailability studies of habitat selection alone do not reveal which habitat has a higher quality for the species (Van Horne 1983; Wiens 1989; White and Garrott 1990). The habitat selected by the animal depends on availability. If only poor quality habitat is available to the animal, the study of habitat selection will describe some habitats as important to the species, while they are simply a choice among poor habitats. Animals might also select poor quality habitats for other reasons, such as poor ability in recognizing good quality habitat (Orians and Wittenberger 1991; Lima and Zollner 1996), site fidelity (Pulliam and Danielson 1991), predation risk (Hughes et al. 1994; 
Creel et al. 2005), or intra and interspecific competition (Hughes et al. 1994; Arjo and Pletscher 2004; Gaillard et al. 2010). In other cases, poor quality habitats can function as ecological traps and be used disproportionally to good quality habitats (Robertson and Hutto 2006; Arlt and Pärt 2007). Without including data on survival or reproductive success in the analysis, we cannot have a clear understanding of habitat quality because the habitat selected by the species could be better than others available, but still not the one that maximizes fitness.

To date, few studies have recognized the value of relating habitat selection to reproductive success (e.g., Pettorelli et al. 2005; McLoughlin et al. 2006; McLoughlin et al. 2007). Few have done so for carnivore species. For example, Mosser et al. (2009) studied lions, Panthera leo, in the Serengeti and demonstrated the importance of using measures of fitness, instead of density, as indices of habitat quality for the species. Here, we relate annual reproductive success of wolf packs living in Yellowstone National Park to their annual third-order habitat selection (Johnson 1980). Wolves (Canis lupus) are social carnivores that live in packs. Usually, the members of a pack collaborate in rearing the pups produced by the alpha pair (Mech 1970). Therefore, we considered the pack as the sample unit, rather than the female giving birth to the young, like in other studies on herbivores (McLoughlin et al. 2006; McLoughlin et al. 2007). We followed the methods proposed by McLoughlin et al. (2006) to identify if the habitat characteristics chosen by a pack increase the chances of survival of its pups. This study enabled us to identify the role of habitat selection on the life history of a large carnivore, adding a missing piece of knowledge to our understanding of the factors that influence an animal's reproductive success. 


\subsection{Methods}

\subsubsection{Study area}

Our study was conducted in the northern range of Yellowstone National Park (YNP), USA. With an area of approximately $1500 \mathrm{~km}^{2}$, the northern range of the park is a complex ecosystem populated by several large carnivores and herbivores (Smith et al. 2003). A well-studied population of wolves, Canis lupus, lives in the area, where it mainly preys upon elk, Cervus elaphus (Smith et al. 2004). For a more comprehensive description of the study area see previous chapters.

\subsubsection{Data collection}

Since wolf reintroduction in YNP in 1995 and 1996, radiotelemetry and reproductive data have been collected every year on all the wolf packs that live in the park Northern Range, as part of the monitoring conducted by the Yellowstone Wolf Project, led by D.W. Smith. We used radiotelemetry locations collected from May 1996 to December 2008 from wolves monitored with both Global Positioning System (GPS) and Very High Frequency (VHF) radiocollars (for more details on wolf capture, handling, and monitoring see Smith et al. 2004; Metz et al. 2011; Stahler et al. 2012). Locations from VHF-radiocollared wolves were collected weekly during most of the study period, with an effort of collecting one location per day from mid-November to mid-December every year. These locations are not autocorrelated because in 24 hours wolves have the ability to travel to any part of their territory (Mech 1970). Locations collected from GPS radiocollars were subsampled to represent daylight animal movements. Subsequently, the two data sets (collected from GPS and VHF radiocollared wolves) were combined and only one location per pack per day was used. These selections were performed with the extension Hawth's Analysis Tools for ArcGIS (Beyer 2004). Each year we recorded the number of pups at den emergence (in May) and the number of pups that survived to the end of the year (December 31). Packs were not considered in the analysis in years when no pups left the den or if the pack dissolved before the end of December. The sample unit was pack/year, leading to a total of 54 observations, each one representing one wolf pack 
(9 total) and one pup-rearing season. Although usually the wolf pup-rearing season is defined as the period going from April to September (Mech and Boitani 2003), in this study we considered as pup-rearing season the time going from May, when the pups leave the den (Young et al. 1944), to December, since in January wolf pups can start dispersing and therefore reach independence (Fuller 1989; Gese and Mech 1991; Mech and Boitani 2003). Radiotelemetry locations were subsampled to cover this time period.

\subsubsection{Statistical analyses}

Overview. - The aim of our study was to assess if the habitat selection performed by a pack influences its pups survival. To reach this aim, our analysis was divided into two steps (following McLoughlin et al. 2006): i) describing the habitat selection of wolves in YNP; ii) linking habitat selection to reproductive success. In the first step, we deviated from McLoughlin et al. (2006) by developing regression models called Resource Utilization Functions (RUFs; see below), instead of the suggested Resource Selection Functions (see Marzluff et al. 2004 for an explanation of the advantages of using RUFs). The regression coefficients from the RUFs summarize wolf habitat preferences and can be used as a basis for better understanding reproductive success. In particular, the second step of our analysis consisted in building regression models where reproductive success was the dependent variable and the regression coefficients obtained from the RUFs were the predictor variables.

Resource Utilization Functions. - RUFs are regression models where the y variable is the intensity of use of locations randomly collected inside an animal's territory and the $\mathrm{x}$ variables are the habitat characteristics available to the animal inside the territory (Marzluff et al. 2004).

The intensity of use of each location inside a territory is obtained by probability density functions called Utilization Distributions (UDs; Van Winkle 1975). UDs are commonly reduced to represent the $95 \%$ of the territory, in order to avoid the possible bias present at the tail of the distribution (Vanak and Gompper 2010). In ArcGIS, we rescaled the UD values to range between 0 , i.e. no use, and 95 , representing the highest 
probability of use. To develop the UDs, we used the fixed kernel technique, with the plug-in method for bandwidth selection (Wand and Jones 1995; Seaman and Powell 1996; Gitzen et al. 2006), using the ks package available for R (R Development Core Team 2012). UDs were developed from each pack/year radiotelemetry locations and locations considered to be extraterritorial forays were discarded from the analysis.

The habitat and topographic characteristics considered as predictors in our models were elevation, slope, distance from major watercourses (rivers), distance from primary roads, vegetation type, and distance from edge. A 30-m Digital Elevation Map (DEM) of the Greater Yellowstone Ecosystem region was used to derive elevation and slope rasters. A 30-m buffer was drawn around each linear feature, watercourses and roads, before developing the rasters (25-m resolution) representing the Euclidean distance to the closest linear features. The vegetation map was derived from a map developed in 2001 by the Multi-Resolution Land Characteristics Consortium (MRLC, http://www.mrlc.gov/nlcd_multizone_map.php). All the vegetation types were combined into two categories: open and forest. Mixed, deciduous, and evergreen forests and woody wetlands belonged to the "forest" category, while all the other vegetation types were classified as "open". Starting from this reclassified map, we developed a map representing the edge between the two vegetation categories and then a raster indicating the distance to the closest edge. All the habitat coverages were developed in ArcGIS (Environmental Systems Research Institute, Redlands, California, USA).

In developing the RUFs, specific for each pack/year, we took into consideration the spatial autocorrelation that is implicit among the locations of a UD by adding a correlation structure (Gaussian, Linear, or Spherical) to the residuals of the model, using the nlme package for R. In order to avoid convergence problems, we also subsampled each UD to 2700 locations. We did so by excluding UD values between 0 and 5 (which represent extremely low use), dividing the remaining values in 9 classes, and subsampling 300 locations per class. Subsequently, we checked for quadratic relationships between the dependent variable and each of the predictor variables and added a squared term if necessary. 
Linking reproductive success and habitat selection. - Once we obtained RUFs for each pack/year (a total of 54 RUFs), we extracted the regression coefficients related to each habitat variable. Then, these coefficients became the predictor variables in a new regression model, where the y variable is a measure of reproductive success (McLoughlin et al. 2006). At this point, we decided to run two separate analyses. In the first analysis, pup survival (i.e., annual reproductive success) was our response variable. Annual reproductive success is the total number of young produced by an animal in one year that survives to dispersal or sexual maturity (Müller et al. 2005; Arlt and Pärt 2007; Stahler et al. 2012). We will call this response variable survival hereafter. The choice of this variable was valuable because it allowed us to assess if wolf habitat selection influenced the overall annual pup production of a pack. In the second analysis, we considered as wolf reproductive success the proportion of pups produced by a pack surviving the year (hereafter prop). In this case, if pack A produces 5 pups and all of them survive to the end of the year, its reproductive success is 1 ; while if pack B produces 10 pups and only 5 of them survive to the end of the year, its reproductive success is 0.5 . This measure of reproductive success was suitable for our goal of relating the habitat choices of adult wolves in a pack to the survival of the pups from den emergence to independence.

Pup survival models. - Since we only had a sample size of 54 observations, we were not able to include all together the coefficients of the six habitat variables as predictors in one model. Instead, we decided to split the predictor variables in two separate models (see Results). Since the response variable survival was not normally distributed, we performed a square root transformation on it. Subsequently, we checked for a year effect on survival. A regression model with survival as the dependent variable and Year as the predictor variable revealed some annual variability in survival $\left(\mathrm{R}^{2}=0.29\right.$; Figure 4.1). Therefore, we added a random effect for Year to our models (Models 1 and 2, Table 4.1). We also inspected these models for outliers and the predictor variables for multicollinearity (threshold: $r=0.6$ ). 
Proportion of surviving pups models. - Similarly to our annual reproductive success analysis, we split the predictor variables in two separate models. A regression model with prop as the dependent variable and Year as the predictor variable revealed strong annual variability in prop $\left(\mathrm{R}^{2}=0.56\right.$; Figure 4.1$)$. The independent variable of our models, prop, contained proportional data. Therefore, we fitted two binomial generalized mixed-effect models, with Year as random effect (Models 3 and 4, Table 4.2). We used diagnosis plots to inspect these models for outliers and also checked the predictor variables for multicollinearity (threshold: $r=0.6$ ). We ran all statistical analyses in $\mathrm{R}$ (R Development Core Team 2012). 


\section{3 $\underline{\text { Results }}$}

The goal of this study was to describe the influence of habitat selection on the reproductive success of wolves in the Northern Range of YNP. We first quantified the variability in reproductive success in the population and then verified if the choice of habitat impacted in any way the number and proportion of wolf pups that survived to the end of the year.

The average $( \pm \mathrm{SE})$ number of pups born in a wolf pack in the study period was $8.5( \pm$ $0.09)$. The average number of pups survived to the end of the year was $5.43( \pm 0.07)$ (Fig.2, upper panel). The proportion of pups survived was overall highly variable, with $31.48 \%$ of the packs/year having a reproductive success $=1$ (Figure 4.2 , lower panel).

The RUFs we developed revealed that wolf packs in our study area never selected in favor or against the vegetation categories we considered. Consequently, vegetation type was not included in any of the subsequent regression models. In all our RUFs, we detected a quadratic relationship between habitat use (UD values) and both elev and roads. Therefore, we added a squared term for each of these variables. The patterns of habitat selection described by these RUFs were overall weak, with most of the coefficients being close to 0 (Figure 4.3). The coefficients for slope and rivers were significant in less than $10 \%$ of our RUFs, while the coefficients for $e$ dge were significant in less than $20 \%$ of the models. elev and elev ${ }^{2}$ showed significance in $25 \%$ of the models. The only pattern that was persistent among packs and years was wolf selection of areas at intermediate distances from primary roads, with roads and roads ${ }^{2}$ being significant in $74 \%$ of the models.

Next, we developed two sets of models to relate the RUFs coefficients to reproductive success. In particular, we built two models for each response variable we considered (survival and prop). The first model contained the coefficients for slope, rivers, and edge as predictor variables. The second included the coefficients for elevation, roads, and the squared terms related to these variables. There was no multicollinearity among the predictor variables and no outliers in any of the models. None of the predictor variables 
had an influence either on survival or prop (all p-values $>0.05$, see Table 4.1 and Table 4.2). 


\subsection{Discussion}

In the past, the mother's body size, its age and social status have been recognized as important factors determining reproductive success (Clutton-Brock 1988; Mech and Boitani 2003; Arlt and Pärt 2007; Rebke et al. 2010). Moreover, Stahler et al. (2012) found positive effects of a female's coat color on its reproductive success, both positive and negative effects of pack size, and negative effects of conspecific density. There are good reasons to believe that habitat selection may impact reproductive success as well. Nevertheless, in our study we were unable to identify any environmental features that would enhance the chances of wolf pups to survive to dispersal.

Reproductive success of wolf packs in the northern range of YNP was overall very variable (Figure 4.2). A large portion of this variability was explained by interannual variation (Figure 4.1). It is interesting to notice how reproductive success was particularly low in 1999, 2005, and 2008. Possible causes for such a low reproductive success might be differences in available habitat, climate, or prey availability characterizing those years. However, we know that the YNP wolf population was inflicted with a canine distemper virus outbreak in those years (Stahler et al. 2012). The reason for such a failure in reproductive success is therefore most probably disease, rather than any habitat-related process.

All the coefficients in the regression models we ran (either with survival or prop as response variable) turned out to be non-significant (Table 4.1 and Table 4.2). This result could be explained in several ways.

First of all, we need to consider that the habitat selection patterns of wolves in our study area were very weak and the variability of the RUFs coefficients was very low (see Results and Figure 4.3). The low variability in the coefficient values might be one of the reasons why we did not detect any relationship between habitat selection and reproductive success. We might have been unable to identify clear habitat selection patterns due to the spatial and temporal scales we considered. The spatial scale we used was the territory of each wolf pack. The activities performed by a pack inside its territory may be too variable for us to detect a clear pattern in habitat selection. Instead, McPhee et 
al. (2012) were able to describe wolf habitat selection by reducing their analysis to one activity, i.e. hunting. Similarly, Ciucci et al. (2003) were able to describe habitat selection of wolves in Italy by analyzing travel paths. Additionally, our temporal scale of analysis was very broad. We considered 13 years of data and pulled together two seasons in each year, summer and early winter. Instead, many studies on wolves found significant patterns in wolf habitat selection based on short-term data (see for example Ciucci et al. 2003; Jędrzejewski et al. 2004; Kuzyk et al. 2004; Latham et al. 2011). The noise created by the year effect in our data (see Figure 4.2 and previous chapters of this dissertation) may be overall too strong to identify any existing relationship between habitat selection and pup survival. In addition, Milakovic et al. (2011) found pronounced differences in wolf habitat selection between summer and early winter. Patterns of habitat selection in our analysis might have been covered because we joined data from these two seasons. In conclusion, pulling together locations describing different activities performed by wolves and data collected in two different seasons might be one of the causes of our failure in distinguishing strong patterns in wolf habitat selection.

Secondly, other factors representing resource selection may need to be taken into consideration. These factors are, for example, prey distribution and intra and interspecific competitor pressure. Wolves are predators that settle their territory based on prey abundance (Mladenoff et al. 1995; Corsi et al. 1999; Mladenoff et al. 1999; Oakleaf et al. 2006). At a territory level, small-scale prey distribution and the availability of habitats that enhance the chances of encountering and killing a prey may be influential on the success of adult wolves in feeding the pups and ultimately in the pup survival. Nevertheless, prey distribution at a small temporal and spatial scale is hard to map and relate to wolf distribution. Similarly, the distribution of good hunting habitats is hard to describe because it might change consistently from year to year (depending, for example, on weather conditions). Competitor pressure is also a relevant process influencing wolf ecology in YNP. Intraspecific strives are one of the major causes of death of wolves in the park and territory overlap among neighboring packs can sometimes be large (Yellowstone Wolf Project, unpublished data). Stahler et al. (2012) found a negative density-dependent effect on reproductive success in the park wolf population. Moreover, 
grizzly bears often take over carcasses of prey killed by wolves, limiting the food income that wolves get from their kills (Smith et al. 2003). Both types of competition may have an effect on wolf reproductive success by creating the need for a trade-off between selection of good quality hunting grounds and safety from competitors. Including some metric of competitors' distribution in the analysis of habitat selection would give valuable insights on the effect of competition on wolf reproductive success.

Lastly, pup survival might be explained not only by the habitat used by the adults in the pack, but also by the habitat characteristics at the den and rendezvous sites. It would be interesting to assess how those characteristics influence pup survival and therefore the reproductive success of a pack.

Conclusions. - Even though our study was not able to detect any effect of habitat selection on reproductive success, we believe that further research may still detect a relationship. McLoughlin et al. (2006) described the positive impact of grassland habitat selection on red deer reproductive success. These habitats were valuable to the species because they represented good quality food. The authors also found a negative correlation between red deer reproductive success and conspecific density. Even though the negative effects of conspecific density may be different between wolves and red deer (wolves kill each other, while deer compete for food), the findings of their study may translate to wolves as well. In other words, we suggest that future studies consider some metrics of prey distribution and catchability and of competitor distribution as predictors of wolf habitat selection. Moreover, conducting the study at smaller spatial and temporal scales could also give important insights on the habitat selection of the species and its effect on reproductive success. 
Table 4.1. Coefficients ( $\beta$ ), standard errors (SE), and p-values (p) for two linear mixed-effect models. The square root of pup survival is the y variable in both models. Year is the random effect. The Resource Utilization Function (RUF) coefficients for slope, rivers, and edge are the predictor variables in Model 1. The RUF coefficients for elev, elev ${ }^{2}$, roads, and roads ${ }^{2}$ are the predictors in Model 2. The sample size is 54 in both models.

\begin{tabular}{|c|c|c|c|c|}
\hline Model & Parameter & $\boldsymbol{\beta}$ & SE & p \\
\hline \multirow{4}{*}{1} & Intercept & 2.18 & 0.16 & 0 \\
\cline { 2 - 5 } & slope & 65.63 & 59.38 & 0.276 \\
\cline { 2 - 5 } & rivers & -8.63 & 30.16 & 0.7763 \\
\cline { 2 - 5 } & edge & 163.86 & 409.82 & 0.6915 \\
\hline \multirow{4}{*}{2} & Intercept & 2.08 & 0.16 & 0 \\
\cline { 2 - 5 } & elev $^{2}$ & -19.61 & 27.32 & 0.4774 \\
\cline { 2 - 5 } & elev $^{2}$ & -153089 & 134795.3 & 0.2634 \\
\cline { 2 - 5 } & roads & 1.4 & 1.64 & 0.3999 \\
\cline { 2 - 5 } & roads $^{2}$ & 119.59 & 100.48 & 0.2416 \\
\hline
\end{tabular}

Table 4.2. Coefficients ( $\beta$ ), standard errors (SE), and p-values (p) for two binomial generalized mixed-effect models. The proportion of pups survived to the end of the year is the y variable in both models. Year is the random effect. The Resource Utilization Function (RUF) coefficients for slope, rivers, and edge are the predictor variables in Model 1. The RUF coefficients for elev, elev ${ }^{2}$,roads, and roads ${ }^{2}$ are the predictors in Model 2. The sample size is 54 in both models.

\begin{tabular}{|c|c|c|c|c|}
\hline Model & Parameter & $\boldsymbol{\beta}$ & SE & p \\
\hline \multirow{4}{*}{3} & Intercept & 0.76 & 0.32 & 0.0174 \\
\cline { 2 - 5 } & slope & 75.49 & 159.73 & 0.6365 \\
\cline { 2 - 5 } & rivers & 29.5 & 81.78 & 0.7183 \\
\cline { 2 - 5 } & edge & 12.9 & 1141.98 & 0.991 \\
\hline \multirow{4}{*}{4} & Intercept & 0.56 & 0.35 & 0.103 \\
\cline { 2 - 5 } & elev & -34.47 & 78.84 & 0.662 \\
\cline { 2 - 5 } & elev $^{2}$ & -254900 & 395500 & 0.519 \\
\cline { 2 - 5 } & roads $^{2}$ & 3.87 & 5.48 & 0.48 \\
\cline { 2 - 5 } & roads $^{2}$ & 223.2 & 274.3 & 0.416 \\
\hline
\end{tabular}



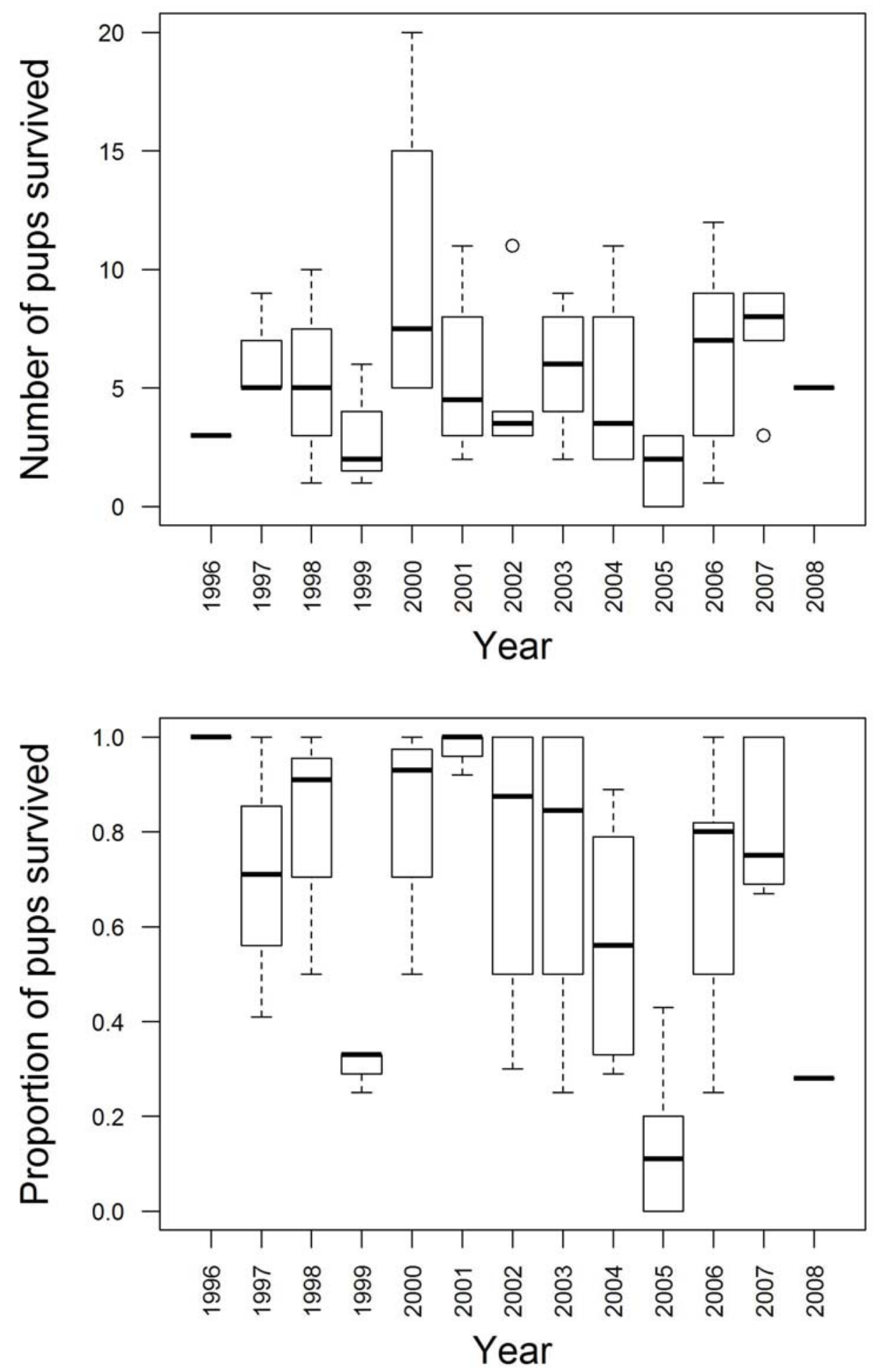

Figure 4.1. Interannual variability in wolf reproductive success. Data are pooled together for all the packs we analyzed. Bold bars represent the median, boxes represent the interquartile range, and dotted lines extend to the range of observed data. 

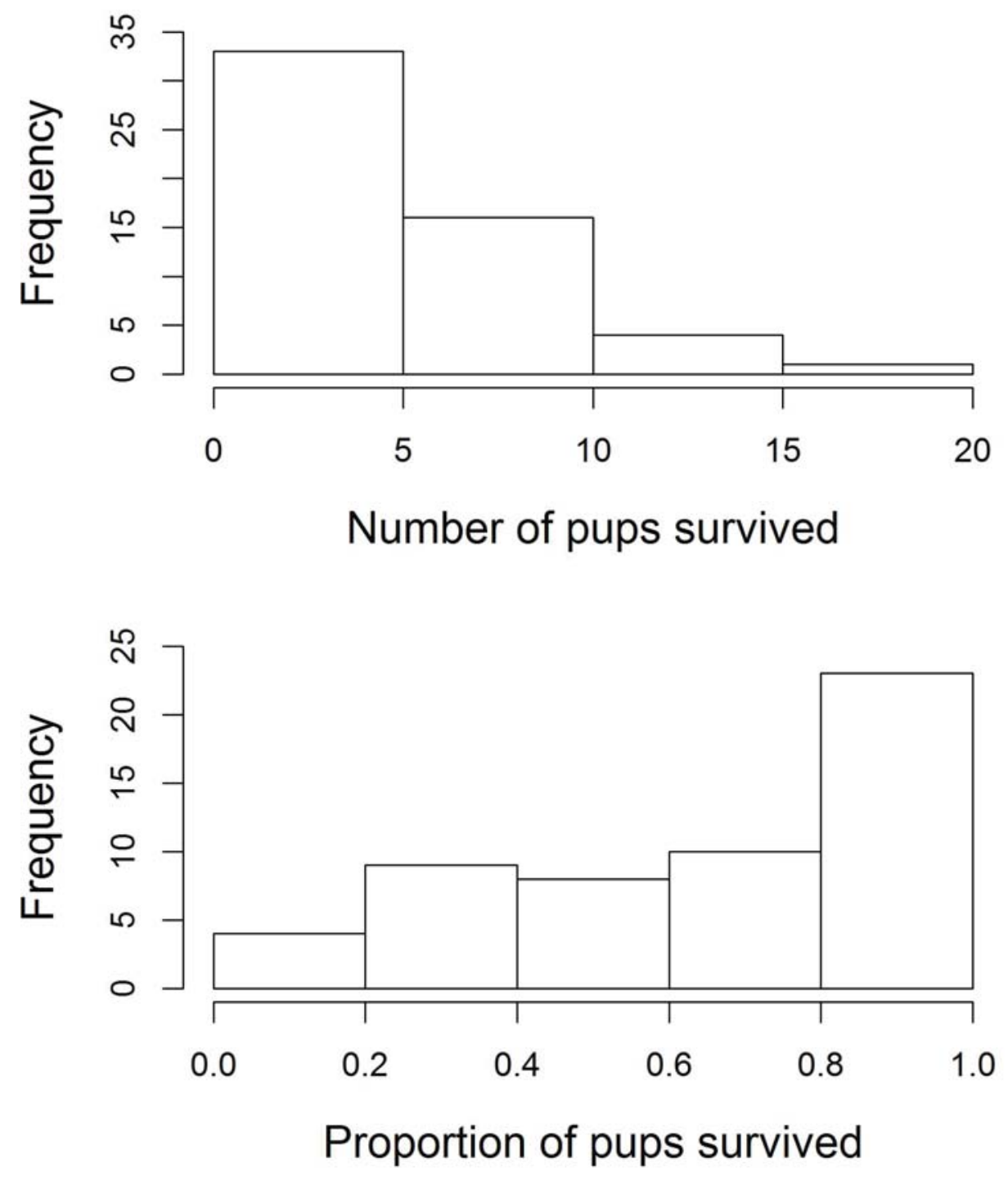

Figure 4.2. Histograms representing the reproductive success of wolf packs in the Northern Range of Yellowstone National Park. Data were pooled together among years (1996-2008) and include nine wolf packs. The sample unit is pack/year, i.e. one pack can be considered multiple times in each graph (with data from different years). 


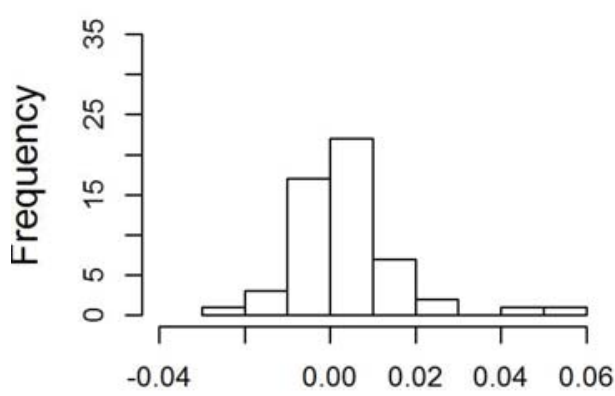

Elevation
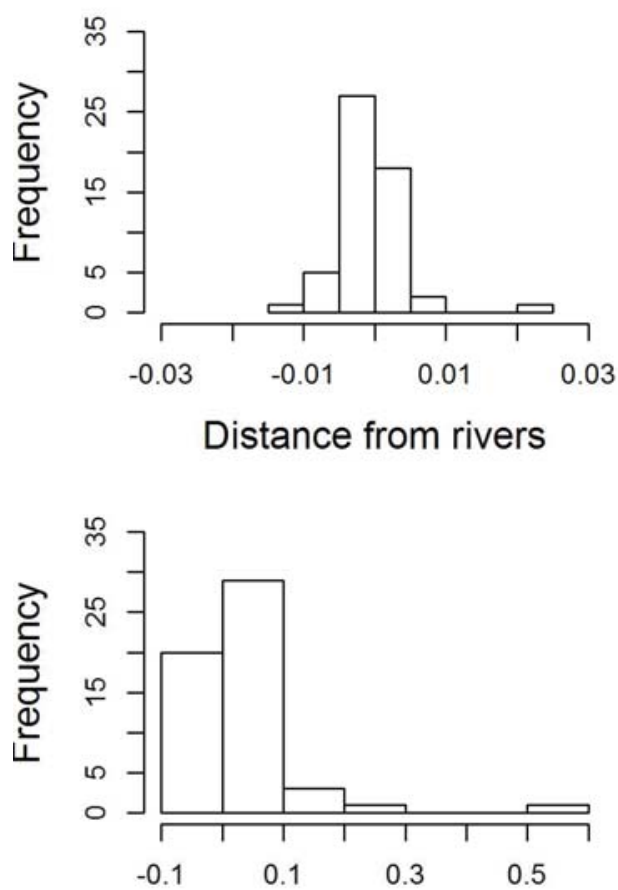

Distance from primary roads
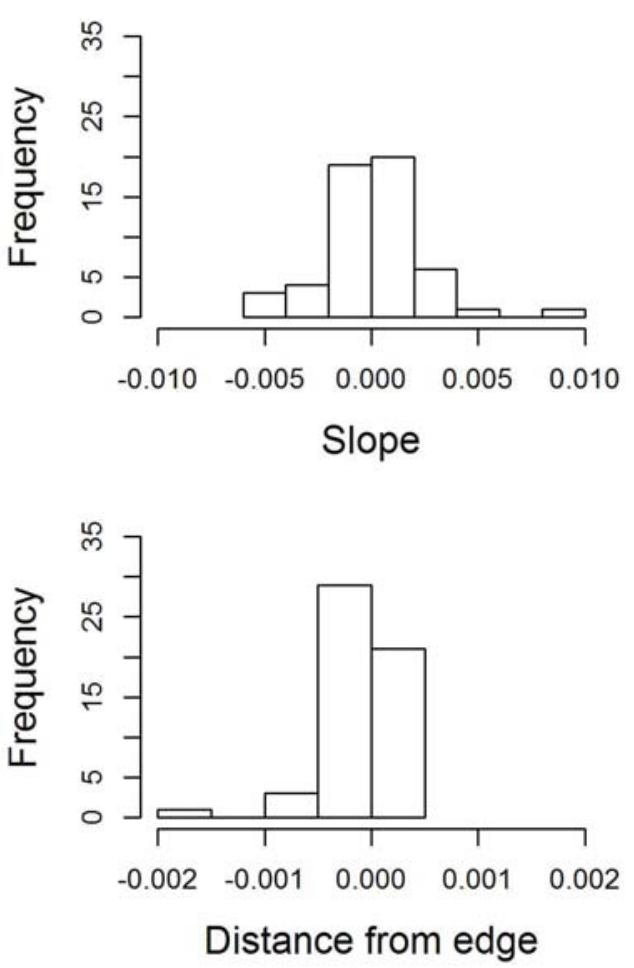

Figure 4.3. Histograms of the distribution of the Resource Utilization Function coefficient values. 


\section{BIBLIOGRAPHY}

Akaike, H. (1974). A new look at the statistical model identification. Automatic Control, IEEE Transactions on 19(6): 716-723.

Arjo, W. M. and Pletscher, D. H. (2004). Coyote and wolf habitat use in northwestern Montana. Northwest Sci. 78(1): 24-32.

Arlt, D. and Pärt, T. (2007). Nonideal breeding habitat selection: a mismatch between preference and fitness. Ecology 88(3): 792-801.

Ballard, W. and Dau, J. (1983). Characteristics of gray wolf, Canis lupus, den and rendezvous sites in southcentral Alaska. Canadian field-naturalist. Ottawa ON 97(3): 299-302.

Balme, G., Hunter, L. and Slotow, R. (2007). Feeding habitat selection by hunting leopards Panthera pardus in a woodland savanna: prey catchability versus abundance. Anim. Behav. 74(3): 589-598.

Beyer, H. L. (2004). Hawth's analysis tools for ArcGIS. URL, http://www.spatialecology.com/htools.

Beyer, H. L., Haydon, D. T., Morales, J. M., Frair, J. L., Hebblewhite, M., Mitchell, M. and Matthiopoulos, J. (2010). The interpretation of habitat preference metrics under useavailability designs. Philosophical Transactions of the Royal Society B: Biological Sciences 365(1550): 2245-2254.

Biro, P. A. and Dingemanse, N. J. (2009). Sampling bias resulting from animal personality. Trends Ecol. Evol. 24(2): 66.

Biro, P. A. and Stamps, J. A. (2008). Are animal personality traits linked to life-history productivity? Trends Ecol. Evol. 23(7): 361-368.

Blanchfield, P. J., Tate, L. S., Plumb, J. M., Acolas, M. L. and Beaty, K. G. (2009). Seasonal habitat selection by lake trout (Salvelinus namaycush) in a small Canadian shield lake: constraints imposed by winter conditions. Aquat. Ecol. 43(3): 777-787.

Camperio Ciani, A. S., Capiluppi, C., Veronese, A. and Sartori, G. (2007). The adaptive value of personality differences revealed by small island population dynamics. European Journal of Personality 21(1): 3-22.

Chamberlain, M. J., Leopold, B. D. and Conner, L. M. (2003). Space use, movements and habitat selection of adult bobcats (Lynx rufus) in central Mississippi. The American Midland Naturalist 149(2): 395-405.

Ciucci, P., Masi, M. and Boitani, L. (2003). Winter habitat and travel route selection by wolves in the northern Apennines, Italy. Ecography 26(2): 223-235.

Clutton-Brock, T. H. (1988). Reproductive success: studies of individual variation in contrasting breeding systems, University of Chicago Press, Chicago, Illinois, USA.

Corsi, F., Duprè, E. and Boitani, L. (1999). A large-scale model of wolf distribution in Italy for conservation planning. Conserv. Biol. 13(1): 150-159.

Cote, J., Clobert, J., Brodin, T., Fogarty, S. and Sih, A. (2010). Personality-dependent dispersal: characterization, ontogeny and consequences for spatially structured populations. Philosophical Transactions of the Royal Society B: Biological Sciences 365(1560): 40654076.

Creel, S., Winnie Jr, J., Maxwell, B., Hamlin, K. and Creel, M. (2005). Elk alter habitat selection as an antipredator response to wolves. Ecology 86(12): 3387-3397.

Dall, S. R. X., Houston, A. I. and McNamara, J. M. (2004). The behavioural ecology of personality: consistent individual differences from an adaptive perspective. Ecol. Lett. 7(8): 734-739. 
Despain, D. G. (1990). Yellowstone vegetation: consequences of environment and history in a natural setting.

Dickson, B. G., Jenness, J. S. and Beier, P. (2005). Influence of vegetation, topography, and roads on cougar movement in southern California. J. Wildl. Manage. 69(1): 264-276.

Eriksen, A., Wabakken, P., Zimmermann, B., Andreassen, H. P., Arnemo, J. M., Gundersen, H., Milner, J. M., Liberg, O., Linnell, J. and Pedersen, H. C. (2009). Encounter frequencies between GPS-collared wolves (Canis lupus) and moose (Alces alces) in a Scandinavian wolf territory. Ecol. Res. 24(3): 547-557.

Estes, R. D. and Goddard, J. (1967). Prey selection and hunting behavior of the African wild dog. The Journal of Wildlife Management: 52-70.

Farnes, P., Heydon, C. and Hansen, K. (1999). Snowpack distribution across Yellowstone National Park. Department of Earth Sciences, Montana State University, Bozeman, Montana, Final report CA: 1268-1261.

Farnes, P. and Romme, W. (1993). Estimating localized SWE on the Yellowstone Northern Range.

Fortin, D., Beyer, H. L., Boyce, M. S., Smith, D. W., Duchesne, T. and Mao, J. S. (2005). Wolves influence elk movements: behavior shapes a trophic cascade in Yellowstone National Park. Ecology 86(5): 1320-1330.

Fritts, S. H., Bangs, E. E. and Gore, J. F. (1994). The Relationship of Wolf Recovery to Habitat Conservation and Biodiversity in the Northwestern United-States. Landscape Urban Plann. 28(1): 23-32.

Fuller, T. K. (1989). Population dynamics of wolves in north-central Minnesota. Wildlife Monographs: 3-41.

Gaillard, J. M., Hebblewhite, M., Loison, A., Fuller, M., Powell, R., Basille, M. and Van Moorter, B. (2010). Habitat-performance relationships: finding the right metric at a given spatial scale. Philosophical Transactions of the Royal Society B: Biological Sciences 365(1550): 2255-2265.

Garshelis, D. L. (2000). Delusions in habitat evaluation: measuring use, selection, and importance. Research techniques in animal ecology: controversies and consequences 2 : 111-164.

Gese, E. M. and Mech, L. D. (1991). Dispersal of wolves (Canis lupus) in northeastern Minnesota, 1969-1989. Canadian Journal of Zoology 69(12): 2946-2955.

Gitzen, R. A., Millspaugh, J. J. and Kernohan, B. J. (2006). Bandwidth selection for fixed-kernel analysis of animal utilization distributions. J. Wildl. Manage. 70(5): 1334-1344.

Hastie, T. J. and Tibshirani, R. J. (1990). Generalized additive models, Chapman \& Hall/CRC.

Hebblewhite, M. and Merrill, E. (2008). Modelling wildlife-human relationships for social species with mixed-effects resource selection models. J. Appl. Ecol. 45(3): 834-844.

Heyes, C. M. and Galef Jr, B. G. (1996). Social learning in animals: The roots of culture, Academic Press.

Hopcraft, J. G. C., Sinclair, A. and Packer, C. (2005). Planning for success: Serengeti lions seek prey accessibility rather than abundance. J. Anim. Ecol. 74(3): 559-566.

Houle, M., Fortin, D., Dussault, C., Courtois, R. and Ouellet, J. P. (2010). Cumulative effects of forestry on habitat use by gray wolf (Canis lupus) in the boreal forest. Landscape Ecol. 25(3): 419-433.

Hughes, J. J., Ward, D. and Perrin, M. R. (1994). Predation risk and competition affect habitat selection and activity of Namib Desert gerbils. Ecology: 1397-1405.

James, A. R. C. and Stuart-Smith, A. K. (2000). Distribution of caribou and wolves in relation to linear corridors. The Journal of Wildlife Management: 154-159. 
Jędrzejewski, W., Jędrzejewska, B., Zawadzka, B., Borowik, T., Nowak, S. and Mysłajek, R. (2008). Habitat suitability model for Polish wolves based on long-term national census. Anim. Conserv. 11(5): 377-390.

Jędrzejewski, W., Niedziałkowska, M., Nowak, S. and Jędrzejewska, B. (2004). Habitat variables associated with wolf (Canis lupus) distribution and abundance in northern Poland. Divers. Distrib. 10(3): 225-233.

Jędrzejewski, W., Schmidt, K., Theuerkauf, J., Jędrzejewska, B. and Okarma, H. (2001). Daily movements and territory use by radio-collared wolves (Canis lupus) in Bialowieza Primeval Forest in Poland. Canadian Journal of Zoology 79(11): 1993-2004.

Johnson, D. H. (1980). The comparison of usage and availability measurements for evaluating resource preference. Ecology 61(1): 65-71.

Joslin, P. W. B. (1967). Movements and home sites of timber wolves in Algonquin Park. Integr. Comp. Biol. 7(2): 279.

Kernohan, B., Gitzen, R. and Millspaugh, J. (2001). Analysis of animal space use and movements. Radio tracking and animal populations. Academic Press, San Diego, California, USA: 125-166.

Kruuk, H. (1972). Surplus killing by carnivores. J. Zool. 166(2): 233-244.

Kuzyk, G. W., Kneteman, J. and Schmiegelow, F. K. A. (2004). Winter habitat use by Wolves, Canis lupus, in relation to forest harvesting in west-central Alberta. The Canadian FieldNaturalist 118(3): 368-375.

Larson, R. J. (1980). Competition, habitat selection, and the bathymetric segregation of two rockfish (Sebastes) species. Ecol. Monogr.: 221-239.

Latham, A. D. M., Latham, M. C., Boyce, M. S. and Boutin, S. (2011). Movement responses by wolves to industrial linear features and their effect on woodland caribou in northeastern Alberta. Ecol. Appl. 21(8): 2854-2865.

Lemke, T., Mack, J. and Houston, D. (1998). Winter range expansion by the northern Yellowstone elk herd. Intermountain Journal of Sciences 4(1/2): 1-9.

Lesmeister, D. B., Gompper, M. E. and Millspaugh, J. J. (2009). Habitat selection and home range dynamics of eastern spotted skunks in the Ouachita Mountains, Arkansas, USA. The Journal of Wildlife Management 73(1): 18-25.

Lesmerises, F., Dussault, C. and St-Laurent, M. H. (2012). Wolf habitat selection is shaped by human activities in a highly managed boreal forest. For. Ecol. Manage. 276: 125-131.

Levins, R. (1968). Evolution in changing environments: some theoretical explorations, Princeton Univ Pr.

Lima, S. L. and Zollner, P. A. (1996). Towards a behavioral ecology of ecological landscapes. Trends Ecol. Evol. 11(3): 131-135.

Mao, J. S., Boyce, M. S., Smith, D. W., Singer, F. J., Vales, D. J., Vore, J. M. and Merrill, E. H. (2005). Habitat selection by elk before and after wolf reintroduction in Yellowstone National Park. J. Wildl. Manage. 69(4): 1691-1707.

Marks, J. S. and Marks, V. S. (1988). Winter habitat use by Columbian sharp-tailed grouse in western Idaho. The Journal of Wildlife Management 52(4): 743-746.

Martin, T. E. (2001). Abiotic vs. biotic influences on habitat selection of coexisting species: climate change impacts? Ecology 82(1): 175-188.

Marzluff, J. M., Millspaugh, J. J., Hurvitz, P. and Handcock, M. S. (2004). Relating resources to a probabilistic measure of space use: forest fragments and Steller's jays. Ecology 85(5): 1411-1427.

Matteson, M. Y. (1992). Denning ecology of wolves in Northwest Montana and southern Canadian Rockies, University of Montana. 
Mauser, D. M., Jarvis, R. L. and Gilmer, D. S. (1994). Movements and habitat use of mallard broods in northeastern California. The Journal of Wildlife Management 58(1): 88-94.

McLoughlin, P., Gaillard, J. M., Boyce, M., Bonenfant, C., Messier, F., Duncan, P., Delorme, D., Moorter, B. V., Saïd, S. and Klein, F. (2007). Lifetime reproductive success and composition of the home range in a large herbivore. Ecology 88(12): 3192-3201.

McLoughlin, P. D., Boyce, M. S., Coulson, T. and Clutton-Brock, T. (2006). Lifetime reproductive success and density-dependent, multi-variable resource selection. Proceedings of the Royal Society B: Biological Sciences 273(1593): 1449.

McPhee, H. M., Webb, N. F. and Merrill, E. H. (2012). Hierarchical predation: wolf (Canis lupus) selection along hunt paths and at kill sites. Canadian Journal of Zoology 90(5): 555-563.

Mech, L. D. (1970). The wolf: the ecology and behavior of an endangered species. The American Museum of Natural History. Garden City, New York, USA.

Mech, L. D. and Boitani, L. (2003). Wolves : behavior, ecology, and conservation, Chicago, University of Chicago Press.

Merrill, S. B. and Mech, L. D. (2003). The usefulness of GPS telemetry to study wolf circadian and social activity. Wildl. Soc. Bull. 31(4): 947-960.

Metz, M. C., Smith, D. W., Vucetich, J. A., Stahler, D. R. and Peterson, R. O. (2011). Seasonal patterns of predation for gray wolves in the multi-prey system of Yellowstone National Park. J. Anim. Ecol.

Milakovic, B., Parker, K. L., Gustine, D. D., Lay, R. J., Walker, A. B. D. and Gillingham, M. P. (2011). Habitat selection by a focal predator (Canis lupus) in a multiprey ecosystem of the northern Rockies. J. Mammal. 92(3): 568-582.

Millspaugh, J. J., Gitzen, R. A., Kernohan, B. J., Larson, M. A. and Clay, C. L. (2004). Comparability of three analytical techniques to assess joint space use. Wildl. Soc. Bull. 32(1): 148-157.

Mladenoff, D. J., Sickley, T. A., Haight, R. G. and Wydeven, A. P. (1995). A Regional Landscape Analysis and Prediction of Favorable Gray Wolf Habitat in the Northern Great-Lakes Region. Conserv. Biol. 9(2): 279-294.

Mladenoff, D. J., Sickley, T. A. and Wydeven, A. P. (1999). Predicting gray wolf landscape recolonization: logistic regression models vs. new field data. Ecol. Appl. 9(1): 37-44.

Mosser, A., Fryxell, J. M., Eberly, L. and Packer, C. (2009). Serengeti real estate: density vs. fitness-based indicators of lion habitat quality. Ecol. Lett. 12(10): 1050-1060.

Müller, M., Pasinelli, G., Schiegg, K., Spaar, R. and Jenni, L. (2005). Ecological and social effects on reproduction and local recruitment in the red-backed shrike. Oecologia 143(1): $37-50$.

Oakleaf, J. K., Murray, D. L., Oakleaf, J. R., Bangs, E. E., Mack, C. M., Smith, D. W., Fontaine, J. A., Jimenez, M. D., Meier, T. J. and Niemeyer, C. C. (2006). Habitat selection by recolonizing wolves in the Northern Rocky Mountains of the United States. J. Wildl. Manage. 70(2): 554-563.

Orians, G. H. (1980). Habitat selection: General theory and applications to human behavior. The evolution of human social behavior: 49-66.

Orians, G. H. and Wittenberger, J. F. (1991). Spatial and temporal scales in habitat selection. Am. Nat.: 29-49.

Otis, D. L. and White, G. C. (1999). Autocorrelation of location estimates and the analysis of radiotracking data. The Journal of Wildlife Management 63(3): 1039-1044.

Paquet, P., Wierzchowski, J. and Callaghan, C. (1996). Effects of human activity on gray wolves in the Bow River Valley, Banff National Park, Alberta. Green, J., C. Pacas, S. Bayley, and L. Cornwell. 
Pauley, G. R., Peek, J. M. and Zager, P. (1993). Predicting white-tailed deer habitat use in northern Idaho. The Journal of Wildlife Management 57(4): 904-913.

Penne, C. R. and Pierce, C. L. (2008). Seasonal distribution, aggregation, and habitat selection of common carp in Clear Lake, Iowa. Trans. Am. Fish. Soc. 137(4): 1050-1062.

Pettorelli, N., Gaillard, J. M., Yoccoz, N. G., Duncan, P., Maillard, D., Delorme, D., Van Laere, G. and Toigo, C. (2005). The response of fawn survival to changes in habitat quality varies according to cohort quality and spatial scale. J. Anim. Ecol. 74(5): 972-981.

Pulliam, H. R. and Danielson, B. J. (1991). Sources, sinks, and habitat selection: a landscape perspective on population dynamics. Am. Nat.: 50-66.

Rachlow, J. L. and Bowyer, R. T. (1998). Habitat selection by Dall's sheep (Ovis dalli): maternal trade-offs. J. Zool. 245(4): 457-465.

Rasmussen, M. L. and Litzgus, J. D. (2010). Habitat selection and movement patterns of spotted turtles (Clemmys guttata): Effects of spatial and temporal scales of analyses. Journal Information 2010(1).

Ream, R. R., Fairchild, M. W., Boyd, D. K. and Blakesley, A. J. (1989). First wolf den in western US in recent history. Northwest. Nat. 70(2): 39-40.

Rebke, M., Coulson, T., Becker, P. H. and Vaupel, J. W. (2010). Reproductive improvement and senescence in a long-lived bird. Proceedings of the National Academy of Sciences 107(17): 7841-7846.

Rich, L. N., Mitchell, M. S., Gude, J. A. and Sime, C. A. (2012). Anthropogenic mortality, intraspecific competition, and prey availability influence territory sizes of wolves in Montana. J. Mammal. 93(3): 722-731.

Ripple, W. J. and Larsen, E. J. (2000). Historic aspen recruitment, elk, and wolves in northern Yellowstone National Park, USA. Biol. Conserv. 95(3): 361-370.

Robertson, B. A. and Hutto, R. L. (2006). A framework for understanding ecological traps and an evaluation of existing evidence. Ecology 87(5): 1075-1085.

Rodríguez, M. A. (1995). Habitat-specific estimates of competition in stream salmonids: a field test of the isodar model of habitat selection. Evol. Ecol. 9(2): 169-184.

Schaller, G. B. (1972). The Serengeti lion: a study of predator-prey relations, University of Chicago Press.

Schumacker, R. E. and Lomax, R. G. (2004). A beginner's guide to structural equation modeling, Lawrence Erlbaum.

Seaman, D. E. and Powell, R. A. (1996). An evaluation of the accuracy of kernel density estimators for home range analysis. Ecology 77(7): 2075-2085.

Seidel, K. D. (1992). Statistical properties and application of a new measure of joint space use for wildlife, University of Washington, Seattle, USA.

Smith, D. W., Drummer, T. D., Murphy, K. M., Guernsey, D. S. and Evans, S. B. (2004). Winter prey selection and estimation of wolf kill rates in Yellowstone National Park, 1995-2000. J. Wildl. Manage. 68(1): 153-166.

Smith, D. W., Peterson, R. O. and Houston, D. B. (2003). Yellowstone after wolves. Bioscience 53(4): 330-340.

Stahler, D. R., MacNulty, D. R., Wayne, R. K., vonHoldt, B. and Smith, D. W. (2012). The adaptive value of morphological, behavioural and life-history traits in reproductive female wolves. J. Anim. Ecol.

Szaro, R., Brawn, J. and Balda, R. (1990). Yearly variation in resource-use behavior by ponderosa pine forest birds. Studies in Avian Biology 13: 226-236.

Thurber, J. M., Peterson, R. O., Drummer, T. D. and Thomasma, S. A. (1994). Gray wolf response to refuge boundaries and roads in Alaska. Wildl. Soc. Bull. 22(1): 61-68. 
Thurston, L. M. (2002). Homesite attendance as a measure of alloparental and parental care by gray wolves (Canis lupus) in Northern Yellowstone National Park, Texas A \& M University.

Van Horne, B. (1983). Density as a misleading indicator of habitat quality. The Journal of Wildlife Management 47(4): 893-901.

Van Winkle, W. (1975). Comparison of several probabilistic home-range models. The Journal of Wildlife Management 39(1): 118-123.

Vanak, A. and Gompper, M. (2010). Multi-scale resource selection and spatial ecology of the Indian fox in a human-dominated dry grassland ecosystem. J. Zool. 281(2): 140-148.

Vucetich, J. A., Hebblewhite, M., Smith, D. W. and Peterson, R. O. (2011). Predicting prey population dynamics from kill rate, predation rate and predator-prey ratios in three wolfungulate systems. J. Anim. Ecol.

Wand, M. P. and Jones, M. C. (1995). Kernel smoothing, Chapman \& Hall/CRC.

White, G. C. and Garrott, R. A. (1990). Analysis of wildlife radio-tracking data, Academic press San Diego.

Whittington, J., Hebblewhite, M., DeCesare, N. J., Neufeld, L., Bradley, M., Wilmshurst, J. and Musiani, M. (2011). Caribou encounters with wolves increase near roads and trails: a time-to-event approach. J. Appl. Ecol. 48(6): 1535-1542.

Whittington, J., St. Clair, C. C. and Mercer, G. (2005). Spatial responses of wolves to roads and trails in mountain valleys. Ecol. Appl. 15(2): 543-553.

Wiens, J. (1989). Spatial scaling in ecology. Funct. Ecol. 3(4): 385-397.

Wockner, G., F. J. Singer, M. Coughenour, and P. Farnes (2002). Application of a snow model for Yellowstone National Park., Natural Resources Ecology Lab, Colorado State University, Fort Collins, USA. http://www.nrel.colostate.edu/projects/yellowstone. Accessed 2005 May 26.

Young, S. P., Goldman, E. A. and Institute, A. W. (1944). The wolves of North America, Dover Publications.

Zuur, A. F., Ieno, E. N., Walker, N. J., Saveliev, A. A. and Smith, G. M. (2009). Mixed effects models and extensions in ecology with R, Springer Verlag.

Zweifel-Schielly, B., Kreuzer, M., Ewald, K. C. and Suter, W. (2009). Habitat selection by an Alpine ungulate: the significance of forage characteristics varies with scale and season. Ecography 32(1): 103-113. 